\title{
An Overview of the Sorption Studies of Contaminants on Poly(Ethylene Terephthalate) Microplastics in the Marine Environment
}

\author{
Francesca Lionetto (D) and Carola Esposito Corcione * (D) \\ Department of Engineering for Innovation, University of Salento, Via Arnesano, 73100 Lecce, Italy; \\ francesca.lionetto@unisalento.it \\ * Correspondence: carola.corcione@unisalento.it
}

\begin{abstract}
Marine pollution is one of the biggest environmental problems, mainly due to single-use or disposable plastic waste fragmenting into microplastics (MPs) and nanoplastics (NPs) and entering oceans from the coasts together with human-made MPs. A rapidly growing worry concerning environmental and human safety has stimulated research interest in the potential risks induced by the chemicals associated with MPs/NPs. In this framework, the present review analyzes the recent advances in adsorption and desorption studies of different contaminants species, both organic and metallic, on MPs made of Poly(Ethylene terephthalate). The choice of PET is motivated by its great diffusion among plastic items and, unfortunately, also in marine plastic pollution. Due to the ubiquitous presence of PET MPS/NPs, the interest in its role as a vector of contaminants has abruptly increased in the last three years, as demonstrated by the very high number of recent papers on sorption studies in different environments. The present review relies on a chemical engineering approach aimed at providing a deeper overview of both the sorption mechanisms of organic and metal contaminants to PET MPs/NPs and the most used adsorption kinetic models to predict the mass transfer process from the liquid phase to the solid adsorbent.
\end{abstract}

Keywords: marine litter; ocean pollution; microplastics; nanoplastics; adsorption; kinetic; organic contaminants; heavy metals; release

\section{Introduction}

Currently, the massive population expansion and the daily use of polymers for producing and consuming non-reusable objects for different applications (packaging, cosmetics, textiles, detergents, greenhouses, mulches, fishing nets, coating and wiring, trays and bottles, covers, bags, and containers) cause wild waste accumulation, with consequent significant complications owing to its management and disposal [1-4]. In specific, the municipal solid waste worldly production passed from 1.3 billions of tons in 1990 to 3.81 billions tons after 25 years [5,6]. Even if the waste flow comes from different sources [7,8], plastics represent a substantial portion of the municipal solid waste. In 2016, about 27.1 million metric tons (Mt) of plastic litters were stored in the European Union (EU), of which $31.1 \%, 41.6 \%$, and $27.3 \%$, were recycled, reused (for energy production), and dumped again in landfill sites, respectively [9]. Among polymer materials, the greatest contribution is provided by thermoplastic polymers, whose consumption (about $80 \%$ of all synthetic polymers) is mostly attributable to packaging and containers, as well as the production of textile fibers [10]. Hence, plastics can be considered highly responsible for waste management issues, not only because of their extensive usage but also because of their short service life together with their long (bio)degradation time [11]. In addition, a great universal worry is due to the plastics' storage in landfills because of their easy accessibility in the environment. In particular, mismanaged plastic waste of polyethylene containers and Poly(Ethylene terephthalate) bottles of beverages, the most common polymers found in urban waste, leads to a huge amount of surface water and seabed marine litter [12]. 
Poly(Ethylene terephthalate), generally labeled as PET, is a thermoplastic polymer of the polyesters family produced by the reaction of ethylene glycol and terephthalic acid under high temperatures and low vacuum pressure. The resulting polyester polymer is characterized by high strength and stiffness, low density, good creep behavior, high chemical resistance, and low cost [13]. Today, PET is one of the world's most commonly used and versatile materials. Global Poly(Ethylene terephthalate) production was 30.3 million tons in 2017 [14], while European PET demand was about 4 million tons in 2018, as compared to the global plastics production of nearly 360 million tons [9]. It is used for bottles, food containers, and synthetic fiber production. It is forecasted that 583 billion PET bottles will be produced in 2021 [15], and for this reason it could be considered one of the most responsible polymers in marine pollution [2]. PET is used not only in the food packaging and textile fields but also in agriculture, electrical applications, and several composite applications in combination with reinforcement fibers for various industrial and civil engineering applications that typically require higher strength and/or higher heat resistance [16-18]. Recently, the interest in fiber-reinforced PET has increased due to its benefits, as compared with thermoset composites, such as damage tolerance, high impact resistance, chemical and solvent resistance, unlimited shelf life, low storage costs, welding ability, and recyclability [19-21].

Plastic pollution in the marine environment has recently been recognized as one of the most impacting threats for the environment, causing numerous hazardous and ecologically negative consequences, such as the entanglement of the marine species within the plastic or their ingestion [22,23]. In particular, juvenile fish, reptiles (i.e., turtles, etc.), and mammals often become entangled in plastic waste with consequent severe damage for the animal growth $[24,25]$ and restriction of movement precluding them from correctly feeding and, in the case of mammals, breathing [26,27]. A wide variety of species have been reported to be harmfully crushed by plastic trash, such as for example marine birds [28,29], sea turtles [30], cetaceans [31], fur seals [24], sharks [25], and filter feeders [32]. Marine birds are very prone to the ingestion of plastic objects that they mistake for food [28,29]. Plastic ingested by these marine organisms remains in the digestive tract and can lead to reduced feeding stimuli, gastrointestinal obstruction, decreased secretion of gastric enzymes, and lower levels of steroid hormones, causing reproduction difficulties [5]. Specific classes of litter found in the oceans, involving the Antarctic [33], have been observed in the sea for at least four decades [34-36].

Microplastics (MPs) are generally defined as polymer particles with a regular or irregular shape and a size ranging between $5 \mathrm{~mm}$ and $1 \mu \mathrm{m}$ and are insoluble in water [37], while bigger particles, such as pellets, are called mesoplastics [26,38,39]. However, a clear and accepted terminology and classification is still under discussion, as well as a standardization of the plastic collection and analysis methods [40]. Microfibers (MFs), very fine fibres (approx. 3-10 $\mu \mathrm{m}$ in diameter), spun as endless filaments can be of both synthetic and natural origin. The size to diameter ratio is also quite high, on the order of $10^{3}$, which is an additional crucial property of MFs [41]. The most common constituents of MPs include polyethylene (PE), polystyrene (PS), polyethylene terephthalate (PET), polyvinylchloride (PVC), and polypropylene (PP), [34,42,43]. MPs generally arise from the plastic pollution of seaside and beaches, deriving from fragmentation phenomena or from powders employed, for example, in cosmetics [44,45]. Both microplastic and mesoplastic litters can be eaten by marine species and, thus, can reach the marine food network. In contrast to macroscopic plastic litters, MPs on the seaside, seabed, or surface water, frequently combined with sand, are complicated to be stored and, at present, there is not an easy and universal method for the calculation of their amount [46]. Furthermore, the degradation of marine MPs due to prolonged external light exposure, mechanical abrasion, and biodegradation can cause the creation of nanoplastics (NPs) with sizes lower than $1 \mu \mathrm{m}$ [47-51]. In particular, marine MPs were investigated by several researchers, and their presence has widely been proven in coastal environments [52-54]. The freshwater system is also considered a potential sink of MPs [55-59]. Zbyszewski and Corcoran [60] reported for the first time the presence of 
MPs in the freshwater system during the coastline of Lake Huron, Canada. Very recently, $\mathrm{Li}$ et al. [61] evidenced that there are different concentrations of MPs in Australia, Asia, North America, and Europe. The current literature underlines that MPs are found in every sea basin around the world, with higher concentrations occurring in intense human activity areas demonstrating that plastic debris transport can be extremely efficient and that the prediction of the plastics' fate is of paramount importance [62]. Additionally, the study and modeling of the transport of MPs in the marine environment has attracting increasing interest [63]. MPs have been detected also in urban atmospheres as well as in remote and pristine environments, showing that atmospheric transport of MPs is also very significant $[64,65]$.

However, even if it is noted in the literature [46] that micro (MPs) and nanoplastics (NPs) represent one of the emergent environmental pollutants and that the release of chemicals/additives used in synthesis of plastics materials may carriage flowing effects on marine species, full knowledge of their impacts on living organisms is still lacking. In detail, the relationship between the migration/dispersion of MPs/NPs from one compartment to another and all the environmental compartments (terrestrial, aquatic, and atmospheric) need to be better analysed. The authors believe that a chemical engineering approach to study this problem can be very useful since it allows the prediction of both the sorption of different contaminants species on MPs/NPs and the diffusion of MPs/NPs in the marine organisms, and, hence, in humans who eat fish. Compared to other papers studying the adsorption on different microplastics, generally PE and PS, the present review focuses on a single polymer, PET, in order to provide a deepen overview of the overall aspects related to the adsorption and desorption studies on PET MPs/NPs. To this aim, this review first analyses the contaminants in the marine environment, then focuses on the sorption mechanisms of organic and metal contaminants to MPs/NPs, indicating the most used adsorption kinetic models to predict the mass transfer process from the liquid phase to the solid adsorbent, with particular regard to the analysis of the adsorption studies of organic and metallic pollutants on the most widely dispersed marine polymer waste, i.e., polyethylene terephthalate MPs.

\section{Poly(Ethylene Terephthalate) Microplastics}

Despite PET representing $10 \%$ of plastic production, its diffusion in marine litter is widely assessed according to public opinion and documented in the literature. The major sources of PET microplastics in the marine environment are bottles and fibers. Bottled water is one sector of the beverage industry that has recently experienced substantial growth, and the consumption of plastic bottles is expected to increase by $20 \%$ by 2021 [66]. It is estimated that 500 billion plastic bottles are used every year, but less than half are recycled [67]. Unfortunately, due to waste mismanagement and illegal dumping, PET bottles are highly present in the marine litter, despite PET being more widely recycled than other polymers. According to the report of Ocean Conservancy International Coastal Cleanup [68], plastic bottles are the third most littered item collected in 2019 around the world. Several beach litter surveys highlight the presence of PET bottles in coastal pollution, with different percentages depending on the climatic period, tourism exploitation, disposal regulation, etc. $[69,70]$. For instance, according to Simeonova and Chuturkova [71], plastic drink bottles represent by weight about $44 \%$ of the Bulgarian Black Sea coastal pollution. Brouwer et al. [72] performed social research in European countries bordering the Mediterranean Sea, Black Sea, and the North Sea. They reported that after cigarette butts, the most frequently recorded litter type by beach visitors is plastic bottles.

Waste with a density higher than that of seawater sinks to the bottom of the sea. For this reason, PET bottles are abundant among deep-sea litter items, as reported for different geographical places, for example in the Caribbean Sea [73], the Mediterranean Sea [74,75], the East China Sea [76], etc. However, PET bottles with closed caps can float and make a long journey, as demonstrated by Duncan et al. [77], who released PET bottles, equipped with GPS and satellite tags, into the Ganges River and the Bay of Bengal. Carried by coastal 
currents, the bottles released into the ocean travelled long distances of up to $2845 \mathrm{~km}$ in 94 days before being dispersed. This demonstrates that plastic pollution is a truly global issue, as a plastic bottle dropped in a river or ocean can travel thousands of miles in a few months.

Recently, PET fibers, which account for 70\% of all synthetic fibers [78] with a global consumption of about 50 Mton/year [79], have been recognized as an emerging source of pollution. They are released in relatively large amounts in wastewaters of common laundry cycles and escape removal from wastewaters in treatment plants due to the very low dimensions (diameters in the 10-20 $\mu \mathrm{m}$ range and masses between 1.7 and $7.0 \mu \mathrm{g}$ ) [79]. PET fibers can generate microfibers through fragmentation and degradation. After entering freshwater and seawater, they may be transported by currents and turbulent hydrodynamic conditions before sinking in the water column [36] and ending up in marine sediments, where they can be ingested by aquatic organisms [80]. Geyer et al. [81] estimated that $5.6 \mathrm{Mt}$ of synthetic microfibers were emitted from apparel washing between 1950 and 2016. Half of this amount was emitted during the last decade, with a compound annual growth rate of $12.9 \%$.

Despite PET being more widely recycled than other polymers, the recycling volume is quite different across countries depending on their policies. There are still several countries where PET recycling is low. Moreover, even if PET is recycled, illegal dumping in the sea is a big problem; additionally, a bottle made of recycled PET can be illegally dumped in the ocean, making all recycling efforts useless. Therefore, the high volume of production of PET and waste mismanagement make PET one of the most polluting plastic materials. The abundance of PET microplastics and their continuous degradation in the marine environment to nanoplastics have raised concerns due to their entering the food chain through multiple routes, increased bioavailability, their impact on low-trophic organisms through the uptake of toxic chemicals, and the increased risks for human health [82]. The issues related to PET MPs/NPs have been less studied than those related to more abundant polymers such as polyethylene (PE) or polystyrene (PS), but interest in research on this topic has been greatly increasing in the last three years, as proved by the very recent literature.

\section{Contaminants in the Marine Environment}

Many chemical contaminants, derived from human activities, are released into the marine environment causing serious damage to water and long-term effects on organisms due to chronic exposure [83]. The most common contaminants present in the microplastics in the marine environment are schematized in Figure 1.

Polychlorinated biphenyls (PCBs) are a wide group of organochlorine compounds largely used in the past in electrical equipment as dielectrics, coolant fluids in electrical apparatus, transformers, switches, capacitors, thermostats, and carbonless copy paper [84,85]. Since 2001, a list of 209 PCB congeners is included in the Stockholm Convention of persistent organic pollutants (POPs) [86,87]. Although they have been banned, PCBs are still present in the environment and are present ubiquitously in biota and sediments $[10,88]$.

Bisphenol A (BPA) is a common constituent of polycarbonate plastic and epoxy resin with a global production of 5.5 million tons per year [89]. BPA is used as an additive to enhance the elasticity, transparency, and durability of some plastic products. It can be released during the production and use of plastic products, and it is found in both aqueous and terrestrial environments and in organisms/animals. BPA is an endocrine-disrupting compound (EDC), affecting the endocrine system and causing adverse effects in humans and animals by either binding to or blocking hormone receptors [89]. It is also associated with cardiovascular disease, reproductive disorders, and breast cancer [90]. 


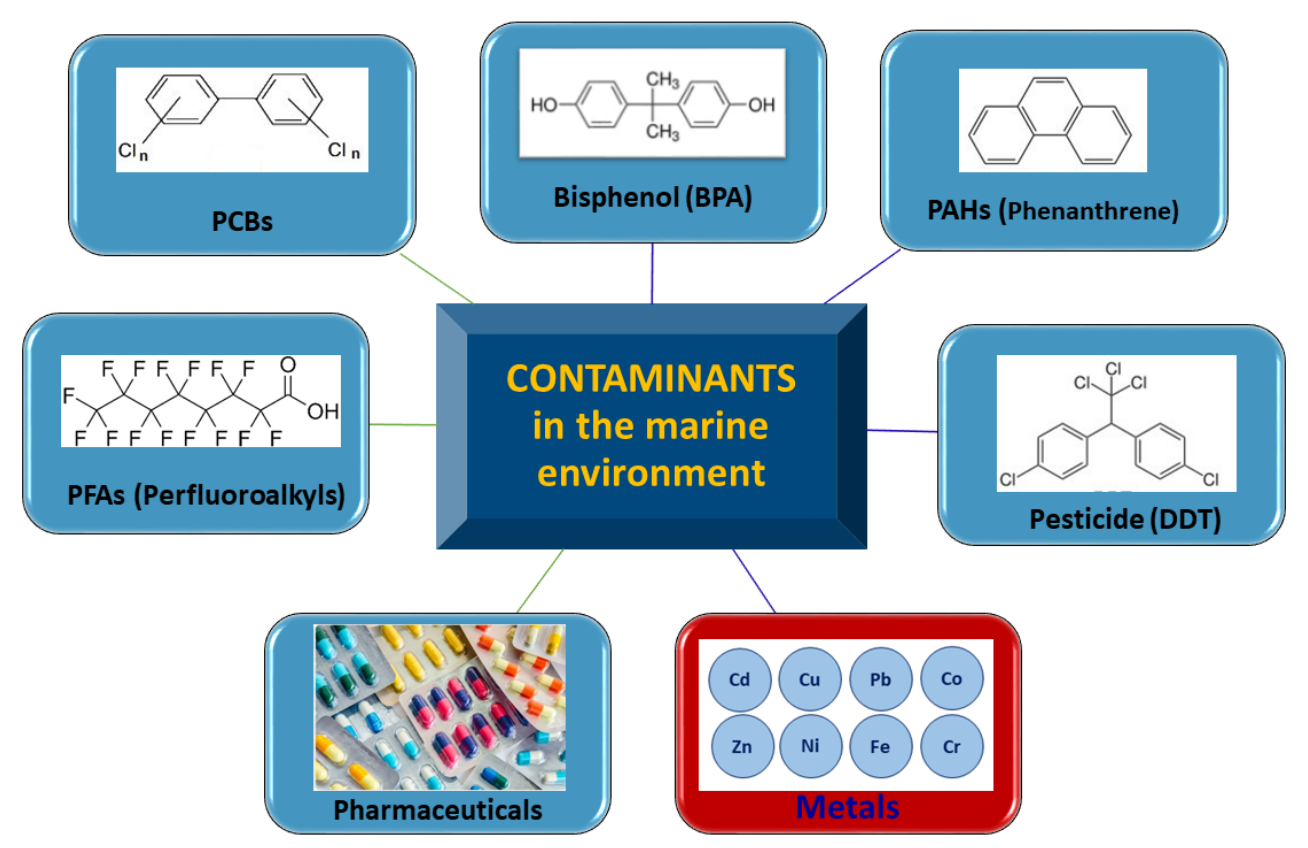

Figure 1. The most common contaminants present in the microplastics in the marine environment.

Polycyclic aromatic hydrocarbons (PAHs) are a family of more than hundred compounds containing multiple aromatic rings, including, for example, naphthalene, anthracene, and phenanthrene [91,92]. They are ubiquitous contaminants generated during the incomplete combustion of organic material and are considered a priority because of their persistence, bioaccumulation, and toxicity [91]. In water, PAHs tend to associate with particles rather than dissolve because of their hydrophobic nature [93]. Exposure to PAHs has also been linked with cancer, cardiovascular disease, and poor fetal development.

Perfluoroalkyl (PFAs) are stable fluorinated compounds that exhibit both polar and apolar moieties. Since they are both water and oil repellent, PFAs are commonly used in the production of commercial stain repellents, surface coatings, firefighting foams, insecticides, and cleaners. Perfluorinated acids (PFAs), including perfluorocarboxylic acids (PFCAs) and perfluorosulfonic acids (PFSAs), have been detected in the blood and tissues of wildlife and humans worldwide, including in remote regions such as the Arctic [94,95]. Elevated exposure to PFAs can impact lipid metabolism, reproduction, and development.

Pesticides are widely used in agriculture, public health control, and domestic environments [96]. It is estimated that approximately 3 billion $\mathrm{kg}$ of pesticides are used annually [97]. Approximately $1 \%$ of the applied pesticides reach their target, while the remaining $99 \%$ enter vegetables, fruits, soils, and water [98]. This dissipation depends on several local factors, including crop type, runoff, leaching, erosion, and climatic conditions. The application strategy and compound characteristics contribute to the fate of pesticide residues [98]. In this context, rainfall is the main factor linked to runoff, washing, transport, and leaching from land to aquatic ecosystems [99,100].

Pharmaceutical compounds have been classified as emerging pollutants for the aquatic ecosystems because they can enter the aquatic environment via different routes, for instance, as wastewater from industries and hospitals, as well as the human body excreting medicines being only partially metabolized into sewage [101]. Together with other chemicals contained in detergents, fabric coatings, cosmetics, and food packaging, pharmaceuticals are considered compounds of emerging concern (CECs) since they may impact aquatic life even in very low concentrations [102]. The most studied pharmaceutical adsorbed on microplastics are amoxicillin, vancomycin, paracetamol [103], and sulfonamide antibiotics [104]. Among CECs, phenol is present in many cleaning and hygiene products and is also used by the plastics industry and agricultural production [103]. Many other 
dangerous organic compounds for marine environments are synthetic dyes used by the textile, cosmetic, pharmaceutical, food, paper, plastic, and printing industries [105-107].

Metals present in the marine environment include not only heavy metals, i.e., metals and metalloids with an atomic weight in the range of $64.5-200.6 \mathrm{~g} / \mathrm{mol}$ and densities greater than $5 \mathrm{~g} / \mathrm{cm}$ [108], but also other lightweight metals and non-metals. Metals in the marine environment may have a natural source, such as the weathering and wear of rocks, soil erosion, or dragging by rainwater, or an anthropogenic origin [109,110]. This latter is related to industrial activities such as electroplating, metal smelting, fertilizer industries, mining operations, pesticides, paper manufacturing, coatings on boats and ships, and pipe corrosion [110-116]. The presence of heavy metals is particularly common where there are high anthropogenic pressures such as harbors and marinas, which are also known to have high abundance of MPs originating from human activities [117]. Titanium is one of the most diffuse metals present in microplastic samples, which may be due to the sorption from the environment or the constitution of the plastic of origin [118]. Ti may be added to the plastic during its manufacture as $\mathrm{TiO}_{2}$ to function as a white pigment or a UV absorber and later be released during the degradation of the material $[119,120]$. The presence of other metals such as $\mathrm{Al}, \mathrm{Fe}, \mathrm{Sn}, \mathrm{Mn}, \mathrm{Pb}$, or $\mathrm{Cr}$ have been found in microplastics from beached sediments $[110,121,122]$. Additionally, cadmium is widely distributed in aquatic environments and has been found to easily accumulate on the surfaces of microplastics [123]. $\mathrm{Cu}$ and $\mathrm{Ag}$ ions are used as biocides in plastics. Copper oxides are particularly used in boat antifouling paints and are then easily dispersed into the marine environment [124-126]. High concentrations of heavy metals contribute to health risks including adverse effects on the nervous, cardiovascular, renal, and reproductive systems and also reduced intelligence [127]. For a detailed review of the potential effects of microplastics and additives of concern to human health, the authors refer to some recent works [128,129].

Generally, the marine concentrations of hazardous substances vary by location and sampling temporal interval, thus making it very difficult to have a reliable mapping. Generally, industrialized areas present higher contaminant values than remote areas. Moreover, only few toxic chemicals have been monitored, compared to the plethora of existing hazardous substances. For example, the European Environmental Agency has monitored the concentration of eight hazardous substances in European seas (cadmium, lead, mercury and the pesticides DDT and lindane, PAH, PCB, and hexachlorobenzene), which were generally considered "low" or "moderate", even if in some cases moderate levels meant that EU environmental quality standards were exceeded and this should be unacceptable for marine organisms [130]. Moreover, a series of hazardous substances (hexachlorobenzene and benzopyrene) could still be found at high concentrations, among others, in some of the European seas, while concentrations of lindane were "high" in the Mediterranean Sea and generally low elsewhere [130].

\section{Sorption Mechanisms of Organic and Metal Contaminants to MPs/NPs}

The different mechanisms of surface interaction between NPs/MPs and contaminants are synthetized in Figure 2. The hydrophobic interactions are non-covalent forces that cause the partition of organic compounds between the aqueous phase and NPs/MPs [131,132]. Generally, the adsorption dominated by hydrophobic interactions follows the linear sorption isotherm [133].

The hydrogen bonding interactions are specific weak electrostatic interactions that exist between a hydrogen atom bonded to a strongly electronegative atom and a lone pair of electrons of another electronegative atom nearby [132]. The sorption by hydrogen bonding happens when there are proton donor and proton acceptor groups, and it could be influenced by the functional groups of NPs/MPs and the organic contaminants [134]. 


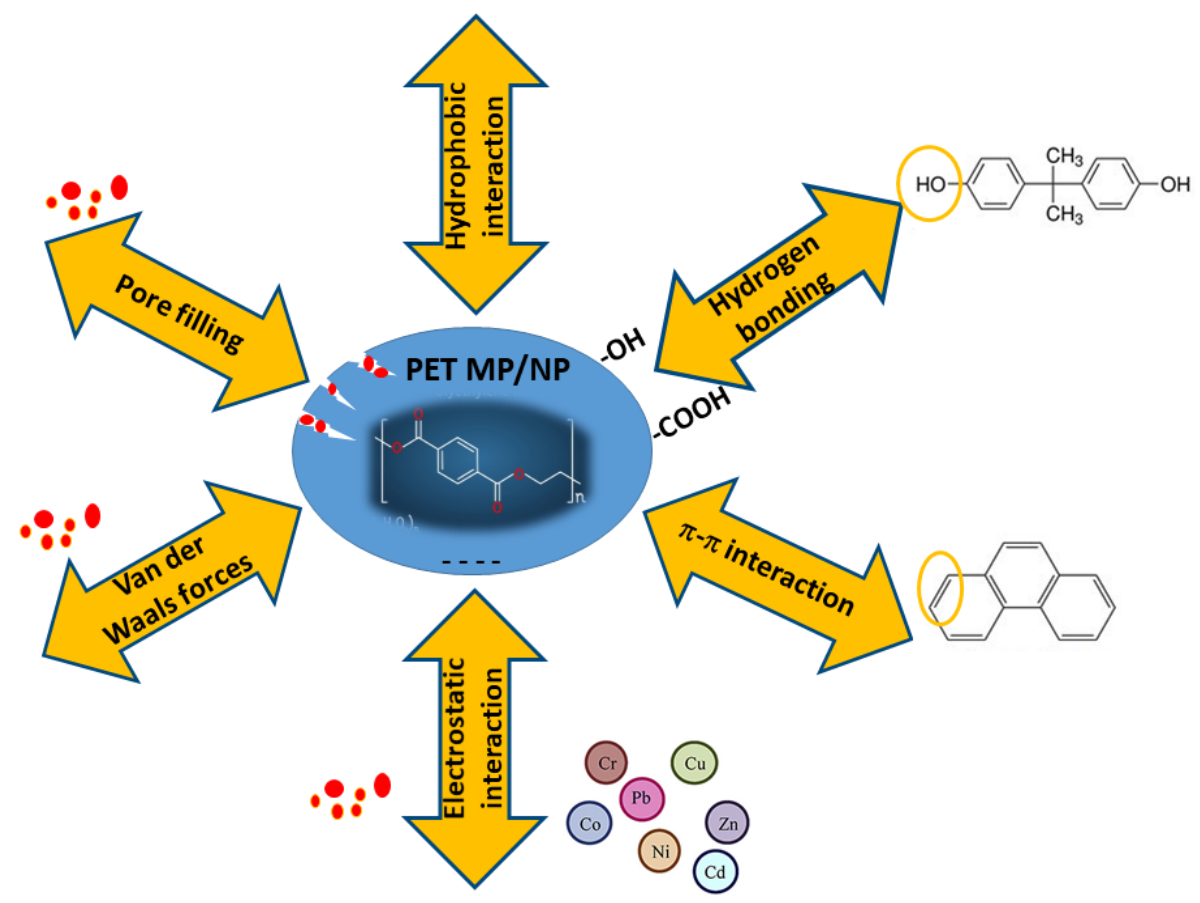

Figure 2. Typical sorption mechanisms between contaminants and micro- and nanoplastics (adapted from $[131,132])$.

NPs/MPs with aromatic rings in the structure, such as polyethylene terephthalate, often present $\pi-\pi$ interactions with aromatic contaminants [134,135], which involve noncovalent bonds. Pharmaceuticals are retained by polymers through $\pi-\pi$ interactions, which is the basis for the development of drug-delivery systems using polymeric nanoparticles [132].

The surface sorption based on the electrostatic interaction arises when both MPs/NPs and organic or metal contaminants have opposite electric charges. The presence of polar groups on the adsorbent surface increases the electrostatic attraction between the hydrophilic domains of the contaminant molecules [132].

Van der Waals forces are non-specific and weak intermolecular forces between molecules $[131,136]$. Typically, aliphatic polymers such as PE and PP interact with organic compounds through van der Waals forces due to the presence of non-specific functional groups [132].

The sorption mechanism, named pore filling, is due to the presence of several pores with different sizes in MPs/NMPs [137-139]. The organic contaminants can penetrate inside the pores, remaining trapped.

The sorption mechanisms of organic contaminants to MPs/NPs depends both on the properties of the MPs/NPs and the organic contaminants and on the chemistry of the solution (i.e., $\mathrm{pH}$, ionic strength, dissolved organic matter) as reported in Figure 3. Among the properties of the MPs/NPs that can affect the sorption mechanisms are the particle size, the polarity, the crystallinity, the glass transition temperature, and the functional groups. Referring to the particle sizes, generally the specific surface area and the amount of sorption sites increase when the particle size decreases. Velzeboer et al. [140] determined an increase of about 1-2 orders of magnitude for NPs with respect to MPs. However, some studies reported that the nanoscale size increased the aggregation of the particles, hence decreasing the specific surface area [140].

Some authors have reported that the sorption mechanism of organic contaminants on MPs/NPs is deeply influenced by the hydrophobicity of MPs [141-143]. In detail, MPs are mostly hydrophobic, and thus they easily adsorb hydrophobic organic contaminants. However, the presence of oxygen-containing groups on the surface of weathered MPs can enhance the polarity, reducing in turn the adsorption of hydrophobic organic contaminants. 
Concerning the crystallinity of the MPs/NPs, it is well known in the literature that the capability and rate of sorption of contaminants by polymers decrease by increasing the grade of crystallinity $[144,145]$. Glass transition temperature also influences MP and contaminant sorption processes [49]. Several authors demonstrated that rubbery polymers are characterized by a greater affinity towards contaminants than glassy polymers $[139,146,147]$. This behavior can be attributed to the high mobility of the rubber state, allowing a major availability for hydrophobic organic compounds [92,148]. On the other hand, glassy polymers have strong sorption sites owing to the presence of internal pores, and consequently they are characterized by a slower release rate of hydrophobic organic compounds. Finally, the functional groups of MPs/NPs can also affect their sorption mechanism as a function of the chemical nature of the group and the contaminant, as reported in detail in [131].

On the other hand, it is important to underline that the properties of organic contaminants (hydrophobicity and hydrophilicity, surface charge and functional groups of the pollutants) also influence the sorption behaviour [131]. For example, Endo et al. [149] showed that organic contaminants with high hydrophobicity can be more readily adsorbed on MPs/NPs. The chemistry of the solution is also responsible for different sorption mechanisms, as confirmed by several results summarized in [131]. In detail, the $\mathrm{pH}$, the ionic strength, and the dissolved organic matter (DOM) of the aqueous solution can affect the sorption mechanism. The $\mathrm{pH}$ of the solution, in fact, establishes the charged state of the organic contaminants and MPs/NPs. This latter phenomenon influences the sorption affinity by means of electrostatic interaction [150]. In addition, the ions of the aqueous solution may contend with the organic contaminants for sorption sites on MPs/NPs, hence influencing the sorption behaviour of organic contaminants by means of MPs/NPs [131]. DOM could influence the sorption of organic compounds by MPs/NPs through complicated interactions, responsible for a strong modification of the MPs/NPs' surface properties [131]. In conclusion, it is important to note that several pollutants are generally present in the aqueous environment, generating further competition for the sorption sites on MPs/NPs.

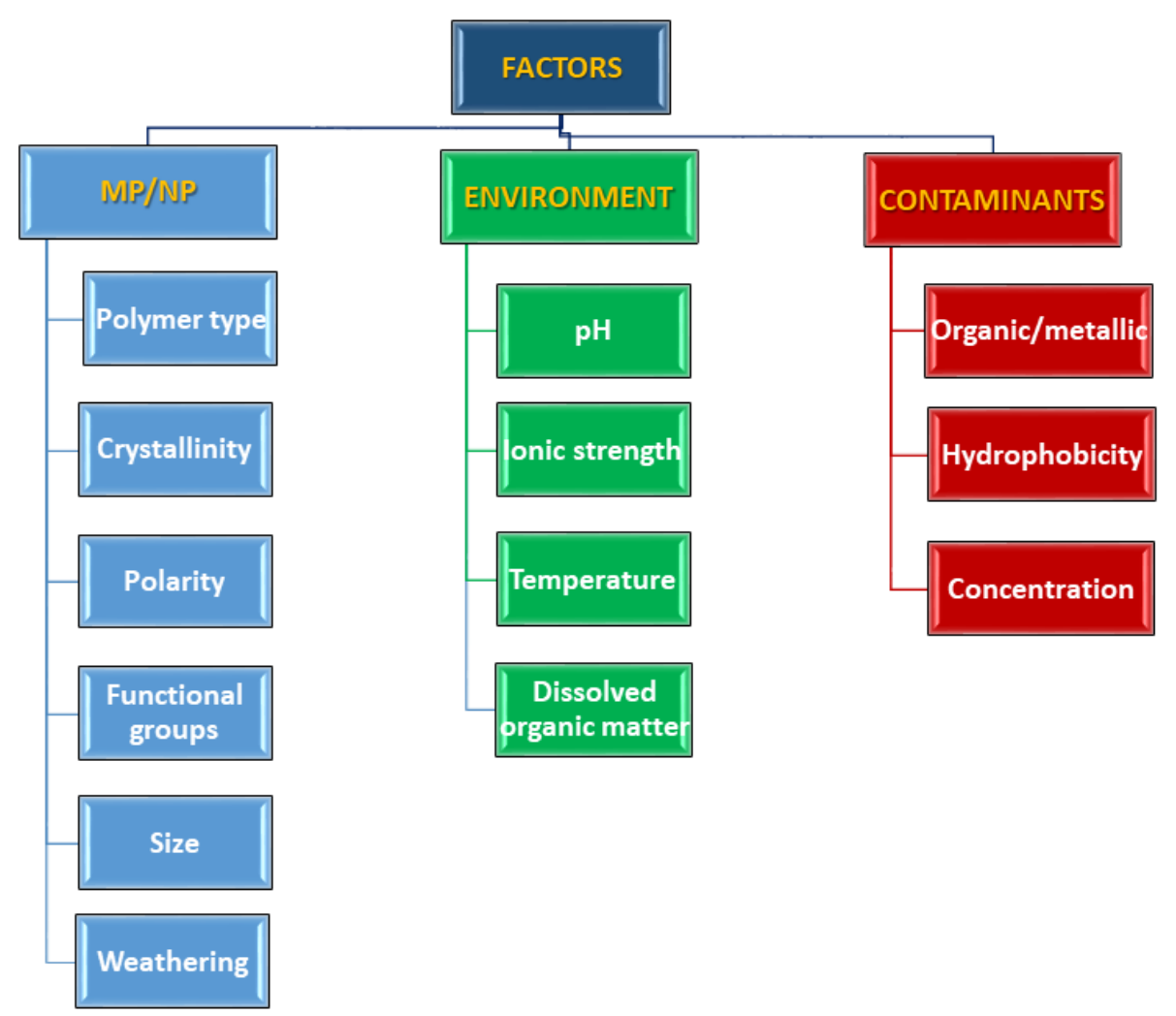

Figure 3. Factors affecting the sorption of contaminants in micro- and nanoplastics (adapted from [151]). 


\section{Adsorption Modelling}

Adsorption is a mass transfer process from the liquid phase to the solid adsorbent. The adsorption kinetic study provides information of the adsorption rate, the performing of the adsorbent, and the mass transfer processes. The possibility to predict the adsorption kinetic of a specific process is crucial for the development of the most suitable adsorption systems. It is well known that the adsorption mass transfer kinetic includes three steps: the external diffusion, the internal one, and the adsorption of the adsorbate in the active sites of the adsorbent diffusion. In first step, the adsorbate moves across the liquid film around the adsorbent specie [152]. The driving force of this stage is the difference between the concentrations of the bulk solution and the surface of the adsorbent. In the second step, the adsorbate specie diffuses in the pores of the adsorbent. Finally, during the last stage, the adsorbate is adsorbed through the active sites of the adsorbent. Among the several adsorption kinetic models proposed, the most used models are empirical without a physical meaning of the specific involved parameters. On the other hand, some other models, even if characterized by parameters with a precise physical meaning, require very complicated solving methods that hinder their utilization, causing in such cases inappropriate applications and solutions. In Table 1, a classification of the most used adsorption kinetic models with the respective reference is reported.

The pseudo-first-order (PFO) model, proposed for the first time by Lagergren in 1898 [2], is an empirical model that has been frequently used to fit the kinetics data and to calculate the amount of chemical adsorbed at the equilibrium $q_{e}$ and the rate constant $k_{1}$, by plotting $\ln \left(\mathrm{q}_{\mathrm{e}}-\mathrm{q}_{\mathrm{t}}\right)$ vs. $\mathrm{t}$, using a linearization method that, in some cases, has determined an erroneous estimation of the parameters [153-156]. However, the adsorption of metal ions and hydrophilic compounds onto microplastics could be represented by the PFO model $[157,158]$. This is probably due to the hydrophobicity of the microplastics, which delays the diffusion of hydrophilic materials into the surface of the microplastics. As a consequence of this behavior, the external/internal diffusion stage can be considered the rate limiting step.

Table 1. Adsorption kinetic models.

\begin{tabular}{|c|c|c|}
\hline Model & Parameters & Ref. \\
\hline Experimental data: $q_{t}, q_{e}, t$ & $\begin{array}{l}\mathrm{q}_{\mathrm{t}} \text { and } \mathrm{q}_{\mathrm{e}} \text { are the amount }\left(\mathrm{mg} \mathrm{g}^{-1}\right) \text { of a target chemical adsorbed per } \\
\text { unit mass of microplastics at time } \mathrm{t}(\mathrm{min}) \text { and at the equilibrium: } \\
\qquad \mathrm{q}_{\mathrm{t}}=\frac{\left(\mathrm{c}_{0}-\mathrm{c}_{\mathrm{t}}\right) \mathrm{V}}{\mathrm{W}} \mathrm{q}_{\mathrm{e}}=\frac{\left(\mathrm{c}_{0}-\mathrm{c}_{\mathrm{e}}\right) \mathrm{V}}{\mathrm{W}} \\
\text { where } c_{0}, c_{t} \text {, and } c_{\mathrm{e}} \text { are the initial concentration }\left(\mathrm{mg} \mathrm{L}^{-1}\right) \text {, concentration } \\
\left(\mathrm{mg} \mathrm{L}^{-1}\right) \text { at time } \mathrm{t}(\mathrm{min}) \text {, and concentration }\left(\mathrm{mg} \mathrm{L}^{-1}\right) \text { at the equilibrium } \\
\text { of a target chemical in liquid phase; } V \text { is the volume (L) of the solution; } \\
\text { W is the mass (g) of microplastics }\end{array}$ & [1] \\
\hline $\begin{array}{l}\text { Pseudo-first-order } \\
\mathrm{q}_{\mathrm{t}}=\mathrm{q}_{\mathrm{e}}\left(1-\mathrm{e}^{-\mathrm{k}_{1} \mathrm{t}}\right)\end{array}$ & $\mathrm{k}_{1}$ is the rate constant $\left(\mathrm{min}^{-1}\right)$ & [159] \\
\hline $\begin{array}{c}\text { Pseudo-second-order } \\
\frac{t}{q_{t}}=\frac{1}{k_{2} q_{e}^{2}}+\frac{t}{q_{e}}\end{array}$ & $\mathrm{k}_{2}$ is the rate constant $\left(\mathrm{g} \mathrm{mg}^{-1} \mathrm{~min}^{-1}\right)$ & [160] \\
\hline $\begin{array}{c}\text { Boyd's film diffusion } \\
\mathrm{F}(\mathrm{t})=1-\left(\frac{6}{\pi^{2}}\right) \sum_{\mathrm{n}=1}^{\infty}\left(\frac{1}{\mathrm{n}^{2}}\right) \exp \left(-\mathrm{n}^{2} \mathrm{Bt}\right)\end{array}$ & $\begin{array}{c}\mathrm{F}(\mathrm{t})=\frac{\mathrm{q}_{\mathrm{t}}}{\mathrm{q}_{\mathrm{e}}} \\
\mathrm{Bt}=0.4977-\ln (1-\mathrm{F}(\mathrm{t})) \\
\text { when } \mathrm{F}(\mathrm{t}) \text { values }>0.85 \\
\mathrm{Bt}=\left(\sqrt{\pi}-\sqrt{\pi-\left(\frac{\pi^{2} \mathrm{~F}(\mathrm{t})}{3}\right)^{2}}\right) \text { when } \mathrm{F}(\mathrm{t}) \text { values }<0.85\end{array}$ & [4] \\
\hline
\end{tabular}

However, the adsorption of hydrophobic organic compounds (such as lubrication oil and polybrominated diphenyl ethers) onto microplastics could be better described by the Ppseudo-second-order (PSO) model [161,162]. Additionally, in this case the linearization of the model presents disseminated errors, responsible for incorrect calculations of the PSO 
model parameters. In order to overcome the limits of both the first- and second-order models, in the 2019 Guo and Wang proposed a mixed order (MO) model [152]. This last model, which represents the overall adsorption process, is based on the following assumptions: (1) an arbitrary stage of the adsorption; (2) the rate controlling step is the diffusion or the adsorption; and (3) an arbitrary initial adsorbate concentration in the solution [152]. The MO model has been successfully used to describe the adsorption of several materials onto microplastics $[157,163]$ by solving the differential equation, implementing the Runge-Kutta method in MATLAB [157] or in the easier Excel software [152].

The internal diffusion models assume that the diffusion of adsorbate within adsorbent is the slowest step. The diffusion of adsorbate in the liquid film around the adsorbent and the adsorption onto the active sites are instantaneous. Among the most used internal diffusion models, in Table 1 the Boyd's intraparticle diffusion model is reported. Boyd et al. proposed, for the first time, an intraparticle diffusion model in the 1947 [164].

In the previous years, Boyd's intraparticle diffusion equation had been applied to describe the internal mass transfer processes. As an example, [165] used Boyd's model to analyze the adsorption process of $\mathrm{Pb}$ (II) onto mansonia wood sawdust. Ala'a et al. [166] applied Boyd's model to study the adsorption of phenol onto PMMA, demonstrating that this process is not controlled by the intraparticle diffusion.

Models for adsorption onto active sites (AAS) are reported in Table 2. These models assume that the adsorption onto active sites is the slowest step, and, thus, the diffusion process is negligible.

Table 2. Adsorption isotherm models.

\begin{tabular}{|c|c|c|}
\hline Model & Parameters & Ref. \\
\hline $\begin{array}{l}\text { Langmuir } \\
\frac{1}{\mathrm{q}_{\mathrm{e}}}=\frac{1}{\mathrm{c}_{\mathrm{e}} \mathrm{q}_{\mathrm{m}} \mathrm{k}_{\mathrm{L}}}+\frac{1}{\mathrm{q}_{\mathrm{m}}}\end{array}$ & $\begin{array}{c}\mathrm{q}_{\mathrm{m}} \text { is the maximum adsorption capacity }\left(\mathrm{mg} \mathrm{g}^{-1}\right) \text { of microplastics } \\
\text { under monolayer adsorption; } \\
\mathrm{k}_{\mathrm{L}} \text { is the surface adsorption equilibrium (Langmuir) constant } \\
\left(\mathrm{L} \mathrm{mg}{ }^{-1}\right) ; \mathrm{q}_{\mathrm{e}} \text { is the amount }\left(\mathrm{mg} \mathrm{g}^{-1}\right) \text { of a target chemical adsorbed } \\
\text { on per unit mass of microplastics at time } \mathrm{t}(\mathrm{min}) ; \\
\mathrm{C}_{\mathrm{e}} \text { is the concentration }\left(\mathrm{mg} \mathrm{L}^{-1}\right) \text { at the equilibrium of a target } \\
\text { chemical in liquid phase }\end{array}$ & [167] \\
\hline $\begin{array}{c}\text { Freundlich } \\
\ln \mathrm{q}_{\mathrm{e}}=\ln \mathrm{k}_{\mathrm{F}}+\frac{1}{\mathrm{n}} \ln \mathrm{c}_{\mathrm{e}}\end{array}$ & $\begin{array}{c}\mathrm{q}_{\mathrm{e}} \text { is the amount }\left(\mathrm{mg} \mathrm{g}^{-1}\right) \text { of a target chemical adsorbed on per unit } \\
\text { mass of microplastics at time } \mathrm{t}(\mathrm{min}) ; \\
\mathrm{c}_{\mathrm{e}} \text { is the concentration }\left(\mathrm{mg} \mathrm{L}^{-1}\right) \text { at the equilibrium of a target } \\
\text { chemical in liquid phase; } \\
\mathrm{k}_{\mathrm{F}} \text { and } \frac{1}{\mathrm{n}} \text { are the Freundlich constants related to adsorption } \\
\text { capacity }\left(\mathrm{L} \mathrm{mg}^{-1}\right) \text { and adsorption intensity }\end{array}$ & [168] \\
\hline $\begin{array}{c}\text { Temkin } \\
\mathrm{q}_{\mathrm{e}}=\frac{\mathrm{RT}}{\mathrm{b}_{\mathrm{T}}} \ln \mathrm{a}_{\mathrm{T}}+\frac{\mathrm{RT}}{\mathrm{b}_{\mathrm{T}}} \ln \mathrm{c}_{\mathrm{e}}\end{array}$ & $\begin{array}{c}\mathrm{q}_{\mathrm{e}} \text { is the amount }\left(\mathrm{mg} \mathrm{g}^{-1}\right) \text { of a target chemical adsorbed on per unit } \\
\text { mass of microplastics at time } \mathrm{t}(\mathrm{min}) ; \\
\text { chemical in liquid phase; } \\
\mathrm{c}_{\mathrm{e}} \text { is the concentration }\left(\mathrm{mg} \mathrm{L}^{-1}\right) \text { at the equilibrium of a target } \\
\text { a } \\
\mathrm{a}_{\mathrm{T}} \text { and } \mathrm{b}_{\mathrm{T}} \text { are the Temkin isotherm constant }\left(\mathrm{L} \mathrm{mg}^{-1}\right) \text { and Temkin } \\
\text { constant }\left(\mathrm{mol}^{-1}\right) \text { related to adsorption heat; } \\
\mathrm{R} \text { is the gas constant with a value of } 8.314 \mathrm{~J} \mathrm{~mol}^{-1} \mathrm{~K}^{-1} ; \mathrm{T} \text { is the } \\
\text { absolute temperature }(\mathrm{K})\end{array}$ & [169] \\
\hline $\begin{array}{l}\text { Dubinin-Radushkevich } \\
\ln \mathrm{q}_{\mathrm{e}}=\ln \mathrm{q}_{\mathrm{D}}-\beta \varepsilon^{2}\end{array}$ & $\begin{array}{l}\mathrm{q}_{\mathrm{e}} \text { is the amount }\left(\mathrm{mg} \mathrm{g}^{-1}\right) \text { of a target chemical adsorbed on per unit } \\
\text { mass of microplastics at time } \mathrm{t}(\mathrm{min}) ; \\
\mathrm{q}_{\mathrm{D}} \text { is the adsorption capacity }\left(\mathrm{mg} \mathrm{g}^{-1}\right) ; \beta \text { is the } \\
\text { Dubinin-Radushkevich model constant }\left(\mathrm{mol}^{2} \mathrm{~J}^{-2}\right) \text { related to } \\
\text { adsorption energy; } \varepsilon \text { is the Polanyi potential calculated by } \\
\qquad \varepsilon=\mathrm{RT} \ln \left(1+\frac{1}{\mathrm{c}_{\mathrm{e}}}\right)\end{array}$ & [170] \\
\hline
\end{tabular}

The Langmuir kinetics model, proposed by Langmuir in 1918 [167] needs to be solved by implementing the Runge-Kutta method in specific programming software, such as MATLAB. However, Al-Jabari [171] applied the Langmuir model to study the 
adsorption kinetics of $\mathrm{Cr}$ (III) onto mineral particles. Marczewski et al. [172] used the same model to analyze the adsorption and desorption kinetics of benzene on carbons, and Marczewski [173] widened the application of the Langmuir model to dilute solutions.

The Freundlich adsorption isotherm model is an empirical law that was conceived to predict the isothermal variation of gaseous adsorption on a solid adsorbent with pressure. This model has been successfully applied for predicting the sorption onto a surface from an aqueous media and gas adsorption on porous surfaces. The key aspect of this model is that it accounts for intermolecular interactions between adsorbates and indicates the heterogeneity of adsorption sites [174]. Temkin isotherm model is able to predict the interaction between adsorbent and adsorbing particle, and, thus, it was successfully used to analyze the equilibrium sorption of the phosphoric acid modified rice husk [169]. The Dubinin-Radushkevich (DR) equation is widely used for the description of adsorption in microporous materials, especially those of a carbonaceous origin. The equation has a semi-empirical origin and is based on the assumptions of a change in the potential energy between the gas and adsorbed phases and a characteristic energy of a given solid. This equation yields a macroscopic behavior of adsorption loading for a given pressure [170].

\section{Adsorption Studies of Organic Pollutants on Poly(Ethylene Terephthalate) MPs/NPs}

As reported in Table 3, several studies are devoted to the adsorption of organic pollutants on PET microplastics, both derived from engineered micropowders, hereafter named "pure MPs", or from the grinding of PET bottles. Liu et al. [175] studied the adsorption behavior of three types of chlorophenols (CPs), which are chlorinated aromatic compounds commonly used for industrial and agricultural production, on pure PET microplastics with a size lower than $150 \mu \mathrm{m}$. The adsorption equilibrium was achieved within $72 \mathrm{~h}$, and the pseudo-second order model was more appropriate to describe the process, which was likely governed by a multi-step mechanism: film diffusion during the first stage, then intra-particle diffusion during the second stage, and dynamic equilibrium during the third stage. The main adsorption mechanisms of undissociated CPs on PET were found to be hydrophobic and hydrogen bonding interactions, which increased and decreased with the chlorine content, respectively. The adsorption capacity was found highly dependent on $\mathrm{pH}$. When $\mathrm{pH}$ increased from to 4 to 10 , the adsorption coefficient decreased close to zero at pH 10 since dichlorophenol (DCP) and trichlorophenol (TCP) were almost completely dissociated and negatively charged. This led to strong electrostatic repulsion with negatively charged PET.

Liu et al. [175] performed adsorption studies not only in ultrapure water but also in natural lake water and seawater, observing a significantly lower adsorption capacity of DCP and TCP on PET MPs than that in ultrapure water. Since multiple chlorophenols often coexist in the environment, the adsorption of a CP mixture in laboratory water was also investigated. The results indicated that the adsorption of each CP by PET was little affected by the presence of other CPs when the concentration of CPs was low.

Godoy et al. [103] studied the sorption and desorption behavior of two antibiotics (amoxicillin and vancomycin), an analgesic (paracetamol), phenol, and two pesticides (atrazine and diuron) on PET chips of $2.7 \mathrm{~mm}$ obtained from the grinding of PET bottles. The kinetic study indicated that phenol and amoxicillin had the highest affinity for PET, even if the sorption process was slow and needed more than 28 days (amoxicillin) or about 21 days (phenol) to reach equilibrium. The equilibrium curves showed a better fit with the Langmuir model, indicating that the sorption was the monolayer type in all the analyzed concentrations. The high adsorption of phenol on PET may be due to the van der Waals and $\pi-\pi$ bonds. These latter are due to the presence of aromatic rings in the structure of a contaminant and polymer [176,177], as it occurs in polystyrene (PS), where the dominant mechanism is given by $\pi-\pi$ bonds [178].

Godoy et al. [103] also performed desorption studies from an initial high concentration of $16 \mathrm{mg} / \mathrm{L}$ at two different temperatures $\left(40{ }^{\circ} \mathrm{C}\right.$ and $\left.82^{\circ} \mathrm{C}\right)$ and three different $\mathrm{pH}$ values $(2,4$, and 6$)$, representing both the environmental and the physiological conditions of a 
marine organism. A pH value equal to 6 is common in most of natural environments; however, in the stomach of mammals a pH value between 2 or 3 is reached [179]. According to experimental results, desorption increased with the temperature and $\mathrm{pH}$.

Song et al. [180] studied the adsorption of petroleum hydrocarbons (PHs) on pure PET MPs with a size in the rage of 50-200 $\mu \mathrm{m}$, which achieved equilibrium within $72 \mathrm{~h}$. They found that the key rate-controlling steps were intraparticle diffusion and liquid film diffusion. For the first mechanism, a process in three stages was proposed. In the first stage, the external mass transfer between the solid and liquid phases lead to surface diffusion. In the second stage, intraparticle diffusion occurred due to the PHs penetration into the inner layer. In the third stage, dynamic equilibrium of sorption and desorption occurred [181]. Unlike previous studies demonstrating the partial reversibility of the desorption of other bisphenol A [90] and phenantrene [182] from microplastics, the sorption of petroleum hydrocarbons on PET was fully reversible and no hysteresis occurred. This implied the environmental risk associated with the release of contaminants in the environment.

Guo et al. [104] studied the sorption of sulfamethoxazole, an antibiotic, on pure PET MPs with a size lower than $150 \mu \mathrm{m}$, which reached equilibrium after $16 \mathrm{~h}$. The sorption capacity decreased with increasing $\mathrm{pH}$ and ionic strength. PET MPs are always negatively charged in alkaline solution, and the surface can be protonated with decreasing $\mathrm{pH}$ [183]. The anionic speciation of sulfamethoxazole increased in alkaline environments, which led to the increasing of the electrostatic repulsion between microplastics and sulfamethoxazole.

The decrease in sorption capacity with increasing ionic strength agrees with the results of Li et al. [184] and Llorca et al. [185] on antibiotics and perfluoroalkys in seawater, respectively. The content of $\mathrm{Na}$ ion increased with increasing salinity and is sorbed without difficulty by electrostatic interaction. The acidic groups of PET MPs may be replaced by protons, which could lead to hydrogen bonding that can explain the reduction of adsorption capacity with increasing ionic strength [186].

Cortes-Arriagada [186] performed a computational study to assess the adsorption mechanism of bisphenol A (BPA) onto PET nanoplastics with an average diameter of $\sim 2.7 \mathrm{~nm}$ by molecular dynamics (MD) simulations. He found that the outer surface of nanoPET had a remarkable nucleophilic nature, allowing one to increase the mass transfer and intraparticle diffusion of BPA into the nanoplastic to form stable complexes by inner and outer surface adsorption. The obtained maximum adsorption energy $(\sim 19 \mathrm{kcal} / \mathrm{mol})$ had a similar order of magnitude of nanostructured adsorbents such as graphene, carbon nanotubes, activated carbon, and inorganic surfaces, indicating the worrying adsorption properties of nanoPET. The adsorption mechanism was driven by the interplay of dispersion and electrostatic effects, which dominated the inner and outer surface adsorption, respectively. The simulation results demonstrated that $\pi-\pi$ stacking was not a reliable interaction mechanism for aromatics on nanoPET. The formed complexes are also highly soluble, and water molecules behaved as non-competitive factors, establishing the high risk of nanoPET to adsorb and migrate pollutants in water ecosystems. Furthermore, the adsorption performance was decreased but not inhibited at a high ionic strength in salt-containing waters. 
Table 3. Adsorption isotherm and kinetic studies on PET microplastics.

\begin{tabular}{|c|c|c|c|c|c|c|c|}
\hline $\begin{array}{c}\text { PET } \\
\text { Source }\end{array}$ & $\begin{array}{l}\text { Size } \\
(\mu \mathrm{m})\end{array}$ & Water & $\begin{array}{c}\text { Pollutant Type and } \\
\text { Content }\end{array}$ & Model & Parameter & $\mathrm{pH}$ & Ref. \\
\hline \multirow[b]{2}{*}{ pure MPs } & \multirow[b]{2}{*}{$<150$} & \multirow[b]{2}{*}{$\begin{array}{l}\text { ultrapure } \\
\text { sea } \\
\text { lake }\end{array}$} & \multirow{2}{*}{$\begin{array}{c}\text { Chlorophenols: } \\
\text { 4-chlorophenol (MCP) } \\
\text { 2,4-dichlorophenol (DCP) } \\
\text { 2,4,6-trichlorophenol } \\
\text { (TCP) } \\
5 \mathrm{mg} / \mathrm{L}\end{array}$} & Langmuir & $\begin{array}{c}\mathrm{q}_{\mathrm{m}}(\mathrm{mg} / \mathrm{g})=2.87(\mathrm{MCP}) \\
0.37(\mathrm{DCP}) ; 0.10(\mathrm{TCP}) \\
\mathrm{k}_{\mathrm{L}}(\mathrm{L} / \mathrm{mg})=3.64(\mathrm{MCP}) \\
81.60(\mathrm{DCP}) ; 92.10(\mathrm{TCP})\end{array}$ & \multirow[b]{2}{*}{8} & \multirow[b]{2}{*}{175} \\
\hline & & & & $\begin{array}{l}\text { Pseudo-second } \\
\text { order }\end{array}$ & $\begin{array}{c}\mathrm{q}_{\mathrm{e}}(\mathrm{mg} / \mathrm{g})=41.60(\mathrm{MCP}) \\
70.30(\mathrm{DCP}) ; 29.80(\mathrm{TCP}) \\
\mathrm{k}_{2}{ }^{*} 10^{3}(\mathrm{~g} /(\mu \mathrm{g} \cdot \mathrm{h})= \\
5.31(\mathrm{MCP}) ; 9.78(\mathrm{DCP}) \\
125.0(\mathrm{TCP})\end{array}$ & & \\
\hline \multirow{2}{*}{ bottles } & \multirow{2}{*}{2700} & \multirow{2}{*}{ Milli-Q } & \multirow{2}{*}{$\begin{array}{c}\text { amoxicillin (AMX), } \\
\text { atrazine(ATZ), diuron } \\
\text { (DIR), paracetamol (PAC) } \\
\text { phenol (PHN), } \\
\text { vancomycin (VAC) } \\
1 \mathrm{mg} / \mathrm{L} \text { (adsorption) }\end{array}$} & Langmuir & $\begin{array}{c}\mathrm{q}_{\mathrm{m}}(\mathrm{mg} / \mathrm{g})=7.18(\mathrm{AMX}) \\
2.80(\mathrm{PHN}) \\
\mathrm{k}_{\mathrm{L}}(\mathrm{L} / \mathrm{mg})=0.30(\mathrm{AMX}) \\
3.19(\mathrm{PHN})\end{array}$ & \multirow[b]{2}{*}{7} & \multirow{2}{*}{103} \\
\hline & & & & $\begin{array}{l}\text { Pseudo-second } \\
\text { order }\end{array}$ & $\begin{array}{c}\mathrm{q}_{\mathrm{e}}(\mathrm{mg} / \mathrm{g})=2.48(\mathrm{AMX}) \\
1.01(\mathrm{PHN}) \\
\mathrm{k}_{2}(\mathrm{mg} / \mathrm{g} \cdot \mathrm{day})=0.005 \\
(\mathrm{AMX}) ; 0.056(\mathrm{PHN})\end{array}$ & & \\
\hline \multirow[t]{2}{*}{ pure MPs } & \multirow[t]{2}{*}{$\begin{array}{l}50- \\
200\end{array}$} & \multirow[t]{2}{*}{ ultrapure } & \multirow[t]{2}{*}{$\begin{array}{l}\text { No. } 10 \text { diesel oil/water } \\
\text { solution } \\
500 \mathrm{mg} / \mathrm{L}\end{array}$} & Langmuir & $\begin{array}{c}\mathrm{q}_{\mathrm{m}}(\mathrm{mg} / \mathrm{g})=1753 \\
\text { (adsorp.); } 28.90 \text { (desorp.) } \\
\mathrm{k}_{\mathrm{L}}(\mathrm{L} / \mathrm{mg})=2.58 \times .15 \\
\text { (adsorp.); } 3.37 \times .15 \\
\text { (desorp.) }\end{array}$ & \multirow[t]{2}{*}{-} & \multirow[t]{2}{*}[180]{} \\
\hline & & & & $\begin{array}{l}\text { Pseudo-second } \\
\text { order }\end{array}$ & $\begin{array}{c}\mathrm{q}_{\mathrm{e}}(\mathrm{mg} / \mathrm{g})=51.90 \mathrm{k}_{2} \\
(\mathrm{~g} /(\mathrm{mg} \cdot \mathrm{h}))=0.09\end{array}$ & & \\
\hline pure MPs & $\begin{array}{l}100- \\
150\end{array}$ & deionized & $\begin{array}{l}\text { sulfamethoxazole } \\
2.4 \mathrm{mg} / \mathrm{L}\end{array}$ & Freundlich & $\mathrm{k}_{\mathrm{F}}(\mathrm{L} / \mathrm{kg})=24.7 n=1.05$ & - & [104] \\
\hline bottles & $<5000$ & $\begin{array}{c}\text { Milli-Q } \\
\text { sea } \\
\text { urban waste } \\
\text { irrigation }\end{array}$ & $\begin{array}{c}\mathrm{Cd}, \mathrm{Co}, \mathrm{Cr}, \mathrm{Cu}, \mathrm{Ni}, \mathrm{Pb}, \mathrm{Zn} \\
1 \mathrm{mg} / \mathrm{L}\end{array}$ & Langmuir & $\begin{array}{l}\mathrm{q}_{\mathrm{m}}(\mathrm{mg} / \mathrm{g})=4.93(\mathrm{~Pb}) \\
\mathrm{k}_{\mathrm{L}}(\mathrm{L} / \mathrm{mg})=0.16(\mathrm{~Pb})\end{array}$ & 7 & [110] \\
\hline \multirow[b]{2}{*}{ pure MPs } & \multirow[b]{2}{*}{65} & \multirow[b]{2}{*}{ Milli-Q } & \multirow{2}{*}{$\begin{array}{c}\mathrm{Cd} \\
60 \mathrm{mg} / \mathrm{L}\end{array}$} & Langmuir & $\begin{array}{c}\mathrm{q}_{\mathrm{m}}(\mathrm{mg} / \mathrm{g})=0.25 \mathrm{k}_{\mathrm{L}} \\
(\mathrm{L} / \mathrm{g})=0.003\end{array}$ & \multirow[b]{2}{*}{6} & \multirow[b]{2}{*}{123} \\
\hline & & & & $\begin{array}{l}\text { Pseudo-second } \\
\text { order }\end{array}$ & $\begin{array}{c}\mathrm{q}_{\mathrm{e}}(\mathrm{mg} / \mathrm{g})=0.11 \\
\mathrm{k}_{2}(\mathrm{~g} / \mathrm{mg} \mathrm{h})=1.96\end{array}$ & & \\
\hline bottles & - & distilled & $\begin{array}{l}\mathrm{Cu}, \mathrm{Zn} \\
5 \mathrm{mg} / \mathrm{L}\end{array}$ & Langmuir & $\begin{array}{c}\mathrm{q}_{\mathrm{m}}(\mathrm{mg} / \mathrm{g})=0.36(\mathrm{Cu}) \\
0.21(\mathrm{Zn}) \\
\mathrm{k}_{\mathrm{L}}(\mathrm{L} / \mathrm{mg})=0.18(\mathrm{Cu}) \\
0.14(\mathrm{Zn})\end{array}$ & - & [187] \\
\hline pellets & 3000 & $\begin{array}{c}\text { sea } \\
\text { immersion, } \\
\text { San Diego } \\
\text { Bay }\end{array}$ & $\begin{array}{c}\mathrm{Mn}, \mathrm{Co}, \mathrm{Ni}, \mathrm{Zn}, \mathrm{Al}, \mathrm{Cr}, \mathrm{Fe} \\
\mathrm{Pb}\end{array}$ & $\begin{array}{l}\text { Pseudo-first } \\
\text { order }\end{array}$ & $\begin{array}{c}\mathrm{q}_{\mathrm{e}}(\mathrm{mg} / \mathrm{g})=0.16(\mathrm{Mn}) \\
0.09(\mathrm{Al}) \\
\mathrm{k}(\mathrm{g} / \mathrm{mg} \mathrm{h})=0.09(\mathrm{Mn}) \\
0.25(\mathrm{Al})\end{array}$ & 8 & [188] \\
\hline
\end{tabular}

\section{Adsorption Studies of Metals on Poly(Ethylene Terephthalate) MPs}

Generally, the sorption uptake of metals on PET MPs reported in the literature is lower than that of organic contaminants. For example, Godoy et al. [110] compared the adsorption of seven heavy metals $(\mathrm{Cd}, \mathrm{Co}, \mathrm{Cr}, \mathrm{Cu}, \mathrm{Ni}, \mathrm{Pb}$, and $\mathrm{Zn}$ ) on five different MPs both in Milli-Q water and natural waters (seawater, urban wastewater, and irrigation water). PET MPs obtained from bottles presented lower adsorption capacity, which was significant with $\mathrm{Pb}$ whose values are reported in Table 3. The adsorption equilibrium was reached after approximately $120 \mathrm{~h}$. The adsorption isotherms were better described by Langmuir model, which indicated that the main adsorption mechanism could be chemical adsorption.

The results obtained by Godoy et al. [110] in natural waters indicated that dissolved organic matter and the electrostatic forces of the polymers may play a major role on metal adsorption on MPs. The results showed an enhancement of metal adsorption in waters 
with high chemical and biological oxygen demands since the adsorption capacity of $\mathrm{Pb}$ increased from $1.25 \mathrm{mg} / \mathrm{g}$ in distilled water to $2.38 \mathrm{mg} / \mathrm{g}$ in seawater, to $3.70 \mathrm{mg} / \mathrm{g}$ in urban wastewater, and to $2.71 \mathrm{mg} / \mathrm{g}$ in irrigation water. These results confirmed the results of Richard et al. [189] who found that metal accumulation on plastic positively correlated with amount of biofilm generated from colonization by fouling organisms. However, the little metal absorption obtained by Godoy et al. [110] on MPs from PET bottles could be due to the PET fillers added to PET against ageing and organism colonization [190].

Zhou et al. [123] studied the effect of $\mathrm{pH}$ on the adsorption of cadmium (Cd(II)) onto five different MPs including pure PET MPs with an average size of $65 \mu \mathrm{m}$. The sorption first increased with a $\mathrm{pH}$ from 2 to 6 and then gradually decreased with a $\mathrm{pH}$ ranging from 6 to 9. The maximum at $\mathrm{pH} 6$ for PET was associated with the point of zero charge, a $\mathrm{pH}_{\mathrm{PZC}}$, value of 5.49 of PET, which is the $\mathrm{pH}$ at which the net charge of total particle surface is equal to zero. For $\mathrm{pH}$ values higher than $\mathrm{pH}_{\mathrm{PZC}}$, electrostatic repulsions occurred decreasing the adsorption amount. Under a high $\mathrm{pH}$ condition, the formed precipitation of $\mathrm{Cd}(\mathrm{OH})^{+} / \mathrm{Cd}(\mathrm{OH})_{2}$ may compete for the active sites on the MPs surface and lead to a decline in $\mathrm{Cd}(\mathrm{II})$ adsorption. Oxygen functional groups (especially the $\mathrm{C}=\mathrm{O}$ and $\mathrm{C}-\mathrm{O}$ groups) played critical roles in the process of Cd adsorption onto MPs [191].

Desorption hysteresis phenomena of cadmium occurred both in the simulated earthworm gut environment and the sediment system, suggesting that metal-contaminated MPs would pose higher ecological risks to macroinvertebrates [123]. PET had lower desorption rates than other microplastics but different form zero, and it was much higher in the simulated gut environment than in the sediment system. As already reported by Zhang et al. [192], Zhou et al. [123] did not observe any formation of new crystalline phases after the $\mathrm{Cd}$ adsorption. This indicated that the microplastic crystallinity may not be the main influencing factor of metal adsorption.

Wang et al. [187] examined the effect of UV irradiation on the metal adsorption of $\mathrm{Cu}^{2+}$ and $\mathrm{Zn}^{2+}$ ions to virgin and aged PET debris in aqueous solution in order to estimate the degradation after sunlight exposure. Generally, they found a higher adsorption for $\mathrm{Cu}^{2+}$ than for $\mathrm{Zn}^{2+}$ and after UV radiation, in agreement with Brennecke et al. [109]. This could be related to the increased surface area and oxygen-containing groups on the surface of UV irradiated MPs. Since the Langmuir model fits the experimental results better than the Freundlich model, this implies that the monolayer adsorption played a significant role in the metal ions removal. The adsorption increased with $\mathrm{pH}$ changing from 3 to 7 due to the high number of charged sites on microplastics. At a $\mathrm{pH}$ higher than 7 , copper and zinc hydroxide precipitation occurred. The adsorption capacities of metal ions were also enhanced with increasing temperatures, which showed that the adsorption processes were endothermic.

\section{Comparison between Marine and Laboratory Adsorption Studies on Poly(Ethylene Terephthalate) MPs}

Most of the adsorption studies with MPs were performed under laboratory-controlled conditions. However, in the field many environmental conditions can vary considerably, such as contaminant concentration, temperature, medium composition, MP degradation, biofilm formation, and the effect of multiple contaminants at the same time.

One main difference between laboratory and field experiments is the equilibration time. Equilibrium is reached much faster under lab conditions in the order of hours or days, while it takes several months in the environment [188,193]. This is likely due to the lower contaminant concentrations in the environment and the constant agitation usually applied in laboratory experiments [134].

Another important difference is the presence of a biofilm which can affect the accumulation and long-range transport of metals in the aquatic environment [194]. To this aim, Rochman et al. [188] deployed five types of plastic pellets (PET, HDPE, LDPE, PVC, and PP of about $5 \mathrm{~mm}$ size) at multiple locations in the urban bay of San Diego for one year. Unlike organic chemical pollutants [147], they found that the accumulation of metals on plastic debris did not differ greatly by polymer type. They explained this result, considering that 
since the distribution of biofilm among different types of plastics is similar, the presence of a biofilm might overwhelm any differences in metal accumulation related to different types of plastic [195]. Moreover, the accumulation of metals was enhanced with time and biofilm accumulation onto the MP surface, since the concentrations of some metals such as $\mathrm{Cr}, \mathrm{Mn}, \mathrm{Co}, \mathrm{Ni}, \mathrm{Zn}$, and $\mathrm{Pb}$ did not reach saturation on at least one plastic type after a one-year immersion in seawater.

Furthermore, the same authors [147] studied the sorption of polycyclic aromatic hydrocarbons (PAHs) and polychlorinated biphenyls (PCBs) on the same five types of plastic pellets immersed in a marine environment for one year. The measured sorption capacity of PET and PVC for PCBs did not change with time, while that for PCBs reached equilibrium after six months, much faster than HDPE, LDPE, and PP, but achieving a significantly lower content. This could be due to the smaller surface area of PET and PVC and to their glassy polymer structure, which did not favor the adsorption/partition of organic compounds $[134,136]$.

The third difference could be ascribed to the source of the investigated PET MPs: bottles or pre-production pellets, here named "pure MPs" in Table 3. For example, Kedzierski et al. [190] immersed PVC, PET, and PBAT (poly-butylene adipate coterephthalate) into the bay of Lorient (France) for 520 days. Unlike OVC, no changes were observed on the PET surface after immersion for more than one year in seawater. According to Kedzierski et al. [190], this difference may arise from PET fillers that protect it against ageing and organism colonization, significantly decreasing its adsorption capacity.

Ateia et al. [196] compared the adsorption of pesticide (atrazine), a pharmaceutical (acetamidophenol), and three perfluoroalkyl substances (PFAS) on a large set of MPs with a size lower than $500 \mu \mathrm{m}$ both in distilled-deionized water and lake water at $\mathrm{pH}=6.5$. Generally, pure MPs had lower normalized uptake values than those of real and weathered MPs [117]. This is due in most cases to a higher surface roughness. Further, those MPs loaded with natural organic matter showed an increased contaminant sorption indicating that laboratory studies underestimate the actual sorption uptake values.

Llorca et al. [84] evaluated for three weeks the adsorption/desorption behavior of polychlorinated biphenyls (PCBs) into PET MPs with a size lower than $600 \mu \mathrm{m}$ in sediment/water systems in marine microcosms. They found a significant sorption rate of PCBs increasing with a lower degree of chlorination. PET presented a superior affinity for PCBs than rubbery polymers, such as PE, due to its glassy nature, related to a high glass transition temperature around $80^{\circ} \mathrm{C}$, and due to the $\pi-\pi$ interactions related to the presence of aromatic groups in its chemical structure. The adsorption/desorption behavior of PCBs onto MPs was fitted by the Freundlich isotherm model.

Although the studies carried out in the field present different results compared to laboratory studies, many of them have been successfully modelled with the sorption models discussed in a previous paragraph, demonstrating the validity of these models [147,188,197].

The maximum adsorption capacity reported in Table 3 is in the range of $0.1-1753 \mathrm{mg} / \mathrm{g}$, depending on the chemical and on the MP size. The lower values have been observed in MPs immersed in the sea with a size of about $3 \mathrm{~mm}$. Usually, the values reported in Table 3 have been determined in laboratory experiments of a few days considering only one contaminant each time, while it is well known that several contaminants can coexist in a particular marine environment, even if at very low concentrations, thus not excluding a synergistic effect on the adsorption. It is plausible to hypothesize that the increased surface area of MPs of a few microns or NPs may lead to higher adsorption and that the long-term immersion in the sea and the presence of a biofilm on the MP/NP can increase the adsorbed chemical amount. As reported by Andrady [49], the potential toxic outcome from ingestion invariably depends on the bioavailability of organic pollutants, the body mass of ingesting organism, the concentration of the organic pollutant "cocktail" in the MP, and their propensity to bioaccumulate in the organism. Even at non-lethal concentrations, 
the interaction among organic and metallic pollutants with PET MPs results in a significant potential environmental and health risk.

\section{Conclusions and Future Perspectives}

The reviewed results highlight that multiple factors affect the adsorption/desorption behavior of pollutants on Poly(Ethylene terephthalate) MPs/NPs, mainly related to the interaction between the chemical structure of PET, contaminants, and the environment. All the results confirm that the adsorption of both organic and metallic pollutants in PET MPs/NPs are important phenomena implying a high risk of concentrating these hazardous chemicals in MPs ingested by marine organisms. PET MPs/NPs can not only transport contaminants in the marine environment but also reach humans along the food chain. Additionally, the contaminant that may be released from MPs/NPs into the environment or human body is a factor of great concern that deserves further investigation. However, due to the complexity of the problem, further long-term studies are still needed in order to deepen the interaction between each pollutant and PET under conditions similar to the real environment, such as seawater and physiological conditions, and taking into account the presence of biofilm.

All the reviewed studies are focused on PET microplastics due to easier detection compared to nanoplastics and to the difficulties in obtaining relevant environmental nanoplastics. The only sorption study on PET NPs was a computational one, performed by molecular dynamics simulations. However, due to the increased surface area of NPs, the adsorption should be comparable or even more pronounced than in MPs.

At the moment, there is little information that MP interactions reduce or increase environmental risks. Consequently, the absence of the evidence of risk can be mistakenly recognized as a declaration of no risk, as also stated by Leslie and Depledge [198]. Indeed, in the authors' opinion, research is still needed to fill the knowledge gap on the source of MPs contaminants, i.e., from additives or from the environment, the synergistic contribution of MP exposure to additives or chemicals found in organisms, and the release mechanisms of toxic chemicals which are still unclear and relatively unexplored. In the authors' opinion, this review may contribute to the increase in awareness on the environmental risks related to ineffective disposal of plastic waste. The authors hope that this review may be useful for planning and implementing novel and efficient plastic waste strategies and water treatment methods for micro- and nanoplastics, thus greatly reducing the risks on the marine environment and human health.

Author Contributions: Conceptualization, F.L. and C.E.C.; methodology, F.L. and C.E.C.; investigation, F.L. and C.E.C.; writing-original draft preparation, F.L. and C.E.C.; writing-review and editing, F.L. and C.E.C.; supervision, C.E.C. All authors have read and agreed to the published version of the manuscript.

Funding: F.L. acknowledges Regione Puglia for funding REFIN-Research for Innovation project "NANOPLASTIC", project no. EF42B557, in the framework of POR PUGLIA FESRFSE 2014/2020 projects.

Institutional Review Board Statement: Not applicable.

Informed Consent Statement: Not applicable.

Conflicts of Interest: The authors declare no conflict of interest.

\section{References}

1. Ferrari, F.; Striani, R.; Minosi, S.; De Fazio, R.; Visconti, P.; Patrono, L.; Catarinucci, L.; Corcione, C.E.; Greco, A. An innovative IoT-oriented prototype platform for the management and valorisation of the organic fraction of municipal solid waste. J. Clean. Prod. 2020, 247, 119618. [CrossRef]

2. Ferrari, F.; Esposito Corcione, C.; Montagna, F.; Maffezzoli, A. 3D Printing of Polymer Waste for Improving People's Awareness about Marine Litter. Polymers 2020, 12, 1738. [CrossRef] [PubMed]

3. Al-Salem, S.M.; Lettieri, P.; Baeyens, J. Recycling and recovery routes of plastic solid waste (PSW): A review. Waste Manag. 2009, 29, 2625-2643. [CrossRef] [PubMed] 
4. Valdés, A.; Mellinas, A.C.; Ramos, M.; Garrigós, M.C.; Jiménez, A. Natural additives and agricultural wastes in biopolymer formulations for food packaging. Front. Chem. 2014, 2, 6. [CrossRef]

5. Beede, D.N.; Bloom, D.E. Economics of the Generation and Management of MSW; National Bureau of Economic Research Working Paper Series; National Bureau of Economic Research: Cambridge, MA, USA, 1995; Working Paper 5116.

6. Ritchie, H.; Roser, M. Plastic Pollution. Available online: https://ourworldindata.org/plastic-pollution (accessed on 18 March 2021).

7. Esposito Corcione, C.; Ferrari, F.; Striani, R.; Visconti, P.; Greco, A. An innovative green process for the stabilization and valorization of organic fraction of municipal solid waste (OFMSW): Optimization of the curing process II part. Appl. Sci. 2019, 9, 3702. [CrossRef]

8. Ferrari, F.; Striani, R.; Visconti, P.; Esposito Corcione, C.; Greco, A. Durability analysis of formaldehyde/solid urban waste blends. Polymers 2019, 11, 1838. [CrossRef]

9. Plastics_The Facts 2019. Available online: https://www.plasticseurope.org/application/files/9715/7129/9584/FINAL_web_ version_Plastics_the_facts2019_14102019.pdf (accessed on 5 December 2020).

10. Dewil, R.; Everaert, K.; Baeyens, J. The European plastic waste issue: Trends and toppers in its sustainable re-use. In Proceedings of the 17th International Congress of Chemical and Process Engineering, Prague, Czech Republic, 27-31 August 2006; pp. 27-31.

11. Issifu, I.; Sumaila, U.R. A Review of the Production, Recycling and Management of Marine Plastic Pollution. J. Mar. Sci. Eng. 2020, 8, 945. [CrossRef]

12. Verma, R.; Vinoda, K.S.; Papireddy, M.; Gowda, A.N.S. Toxic pollutants from plastic waste-a review. Procedia Environ. Sci. 2016, 35, 701-708. [CrossRef]

13. Bjorksten, J. Polyesters and Their Applications; Reinhold Publishing Corporation: New York, NY, USA, 1956.

14. Polyethylene Terephthalate (PET): Production, Price, Market and Its Properties. Available online: https://www.plasticsinsight. com/resin-intelligence/resin-prices/polyethylene-terephthalate/ (accessed on 7 April 2021).

15. Tiseo, I. Global PET Bottle Production 2004-2021. Available online: https://www.statista.com/statistics/723191/production-ofpolyethylene-terephthalate-bottles-worldwide/ (accessed on 28 March 2021).

16. Dell'Anna, R.; Lionetto, F.; Montagna, F.; Maffezzoli, A. Lay-up and consolidation of a composite pipe by in situ ultrasonicwelding of a thermoplastic matrix composite tape. Materials 2018, 11, 786. [CrossRef]

17. Greco, A.; Lionetto, F.; Maffezzoli, A. Processing and characterization of amorphous polyethylene terephthalate fibers for the alignment of carbon nanofillers in thermosetting resins. Polym. Compos. 2015, 36, 1096-1103. [CrossRef]

18. Cascardi, A.; Dell'Anna, R.; Micelli, F.; Lionetto, F.; Aiello, M.A.; Maffezzoli, A. Reversible techniques for FRP-confinement of masonry columns. Constr. Build. Mater. 2019, 225, 415-428. [CrossRef]

19. Lionetto, F.; Pappadà, S.; Buccoliero, G.; Maffezzoli, A. Finite element modeling of continuous induction welding of thermoplastic matrix composites. Mater. Des. 2017, 120, 212-221. [CrossRef]

20. Lionetto, F.; Moscatello, A.; Totaro, G.; Raffone, M.; Maffezzoli, A. Experimental and numerical study of vacuum resin infusion of stiffened carbon fiber reinforced panels. Materials 2020, 13, 4800. [CrossRef]

21. Lionetto, F.; Montagna, F.; Maffezzoli, A. Out-of-Plane Permeability Evaluation of Carbon Fiber Preforms by Ultrasonic Wave Propagation. Materials 2020, 13, 2684. [CrossRef]

22. Webb, H.K.; Arnott, J.; Crawford, R.J.; Ivanova, E.P. Plastic degradation and its environmental implications with special reference to Poly(Ethylene terephthalate). Polymers 2013, 5, 1-18. [CrossRef]

23. Derraik, J.G.B. The pollution of the marine environment by plastic debris: A review. Mar. Pollut. Bull. 2002, 44, 842-852. [CrossRef]

24. Pemberton, D.; Brothers, N.P.; Kirkwood, R. Entanglement of Australian fur seals in man-made debris in Tasmanian waters. Wildl. Res. 1992, 19, 151-159. [CrossRef]

25. Sazima, I.; Gadig, O.B.F.; Namora, R.C.; Motta, F.S. Plastic debris collars on juvenile carcharhinid sharks (Rhizoprionodon lalandii) in southwest Atlantic. Mar. Pollut. Bull. 2002, 44, 1149-1151. [CrossRef]

26. Gregory, M.R.; Andrady, A.L. Plastics in the marine environment. Plast. Environ. 2003, 379-401.

27. Gregory, M.R. Environmental implications of plastic debris in marine settings-Entanglement, ingestion, smothering, hangers-on, hitch-hiking and alien invasions. Philos. Trans. R. Soc. B Biol. Sci. 2009, 364, 2013-2025. [CrossRef]

28. Azzarello, M.Y.; Van Vleet, E.S. Marine birds and plastic pollution. Mar. Ecol. Prog. Ser. 1987, 37, 295-303. [CrossRef]

29. Blight, L.K.; Burger, A.E. Occurrence of plastic particles in seabirds from the eastern North Pacific. Mar. Pollut. Bull. 1997, 34, 323-325. [CrossRef]

30. Barreiros, J.P.; Barcelos, J. Plastic ingestion by a leatherback turtle Dermochelys coriacea from the Azores (NE Atlantic). Mar. Pollut. Bull. 2001, 42, 1196-1197. [CrossRef]

31. Baird, R.W.; Hooker, S.K. Ingestion of plastic and unusual prey by a juvenile harbour porpoise. Can. J. Fish. Aquat. Sci. 2000, 51, 172-178. [CrossRef]

32. Moore, C.J.; Moore, S.L.; Leecaster, M.K.; Weisberg, S.B. A comparison of plastic and plankton in the North Pacific central gyre. Mar. Pollut. Bull. 2001, 42, 1297-1300. [CrossRef]

33. Zarfl, C.; Matthies, M. Are marine plastic particles transport vectors for organic pollutants to the Arctic? Mar. Pollut. Bull. 2010, 60, 1810-1814. [CrossRef] 
34. Horton, A.A.; Dixon, S.J. Microplastics: An introduction to environmental transport processes. Wiley Interdiscip. Rev. Water 2018, 5, e1268. [CrossRef]

35. Barnes, D.K.A.; Galgani, F.; Thompson, R.C.; Barlaz, M. Accumulation and fragmentation of plastic debris in global environments. Philos. Trans. R. Soc. B Biol. Sci. 2009, 364, 1985-1998. [CrossRef]

36. Thompson, R.C.; Olsen, Y.; Mitchell, R.P.; Davis, A.; Rowland, S.J.; John, A.W.G.; McGonigle, D.; Russell, A.E. Lost at sea: Where is all the plastic? Science 2004, 304, 838. [CrossRef]

37. Magnusson, K.; Norén, F. Screening of Microplastic Particles in and Down-Stream a Wastewater Treatment Plant; IVL Swedish Environmental Research Institute Report; IVL Swedish Environmental Research Institute: Stockholm, Sweden, 2014.

38. Acharya, S.; Rumi, S.S.; Hu, Y.; Abidi, N. Microfibers from synthetic textiles as a major source of microplastics in the environment: A review. Text. Res. J. 2021. [CrossRef]

39. Zilla, G.; Marc, N. Briefing Note on Microplastics Literature Review. 2020. Available online: https:/ / www.applia-europe.eu/ images/Library/2020-10-28_APPLiA-RISE_Literature_Review_Final_for_release-3.pdf (accessed on 16 April 2021).

40. Hartmann, N.B.; Hüffer, T.; Thompson, R.C.; Hassellöv, M.; Verschoor, A.; Daugaard, A.E.; Rist, S.; Karlsson, T.; Brennholt, N.; Cole, M. Are we speaking the same language? Recommendations for a definition and categorization framework for plastic debris. Environ. Sci. Technol. 2019, 53, 1039-1047. [CrossRef] [PubMed]

41. Lares, M.; Ncibi, M.C.; Sillanpää, M.; Sillanpää, M. Occurrence, identification and removal of microplastic particles and fibers in conventional activated sludge process and advanced MBR technology. Water Res. 2018, 133, 236-246. [CrossRef] [PubMed]

42. Bolan, N.S.; Kirkham, M.B.; Halsband, C.; Nugegoda, D.; Ok, Y.S. Particulate Plastics in Terrestrial and Aquatic Environments; CRC Press: Boca Raton, FL, USA, 2020; ISBN 1000081419.

43. Le, T.T.Y.; Grabner, D.; Nachev, M.; Peijnenburg, W.J.G.M.; Hendriks, A.J.; Sures, B. Modelling copper toxicokinetics in the zebra mussel, Dreissena polymorpha, under chronic exposures at various $\mathrm{pH}$ and sodium concentrations. Chemosphere 2021, 267, 129278. [CrossRef]

44. Moore, C.J. Synthetic polymers in the marine environment: A rapidly increasing, long-term threat. Environ. Res. 2008, 108, 131-139. [CrossRef]

45. Park, J.W.; Lee, S.J.; Hwang, D.Y.; Seo, S. Recent Purification Technologies and Human Health Risk Assessment of Microplastics. Materials 2020, 13, 5196. [CrossRef]

46. Kumar, M.; Chen, H.; Sarsaiya, S.; Qin, S.; Liu, H.; Awasthi, M.K.; Kumar, S.; Singh, L.; Zhang, Z.; Bolan, N.S. Current research trends on micro-and nano-plastics as an emerging threat to global environment: A review. J. Hazard. Mater. 2020, $409,124967$. [CrossRef]

47. Gigault, J.; Pedrono, B.; Maxit, B.; Ter Halle, A. Marine plastic litter: The unanalyzed nano-fraction. Environ. Sci. nano 2016, 3, 346-350. [CrossRef]

48. Frias, J.; Nash, R. Microplastics: Finding a consensus on the definition. Mar. Pollut. Bull. 2019, 138, 145-147. [CrossRef]

49. Andrady, A.L. The plastic in microplastics: A review. Mar. Pollut. Bull. 2017, 119, 12-22. [CrossRef]

50. De Souza Machado, A.A.; Kloas, W.; Zarfl, C.; Hempel, S.; Rillig, M.C. Microplastics as an emerging threat to terrestrial ecosystems. Glob. Chang. Biol. 2018, 24, 1405-1416. [CrossRef]

51. Galafassi, S.; Nizzetto, L.; Volta, P. Plastic sources: A survey across scientific and grey literature for their inventory and relative contribution to microplastics pollution in natural environments, with an emphasis on surface water. Sci. Total Environ. 2019, 693, 133499. [CrossRef] [PubMed]

52. Aslam, H.; Ali, T.; Mortula, M.M.; Attaelmanan, A.G. Evaluation of microplastics in beach sediments along the coast of Dubai, UAE. Mar. Pollut. Bull. 2020, 150, 110739. [CrossRef] [PubMed]

53. Gallo, F.; Fossi, C.; Weber, R.; Santillo, D.; Sousa, J.; Ingram, I.; Nadal, A.; Romano, D. Marine litter plastics and microplastics and their toxic chemicals components: The need for urgent preventive measures. Environ. Sci. Eur. 2018, 30, 1-14. [CrossRef]

54. Zhang, P.; Wei, S.-S.; Zhang, J.-B.; Ou, Z.; Yang, Y.-Q.; Wang, M.-Y. Occurrence, Composition, and Relationships in Marine Plastic Debris on the First Long Beach Adjacent to the Land-Based Source, South China Sea. J. Mar. Sci. Eng. 2020, 8, 666. [CrossRef]

55. Wu, P.; Huang, J.; Zheng, Y.; Yang, Y.; Zhang, Y.; He, F.; Chen, H.; Quan, G.; Yan, J.; Li, T. Environmental occurrences, fate, and impacts of microplastics. Ecotoxicol. Environ. Saf. 2019, 184, 109612. [CrossRef]

56. Wagner, M.; Lambert, S. Freshwater Microplastics: Emerging Environmental Contaminants? Springer Nature: Heidelberg, Germany, 2018.

57. Strungaru, S.-A.; Jijie, R.; Nicoara, M.; Plavan, G.; Faggio, C. Micro-(nano) plastics in freshwater ecosystems: Abundance, toxicological impact and quantification methodology. TrAC Trends Anal. Chem. 2019, 110, 116-128. [CrossRef]

58. Prokić, M.D.; Radovanović, T.B.; Gavrić, J.P.; Faggio, C. Ecotoxicological effects of microplastics: Examination of biomarkers, current state and future perspectives. TrAC Trends Anal. Chem. 2019, 111, 37-46. [CrossRef]

59. Guerranti, C.; Perra, G.; Martellini, T.; Giari, L.; Cincinelli, A. Knowledge about microplastic in Mediterranean tributary river ecosystems: Lack of data and research needs on such a crucial marine pollution source. J. Mar. Sci. Eng. 2020, 8, 216. [CrossRef]

60. Zbyszewski, M.; Corcoran, P.L. Distribution and degradation of fresh water plastic particles along the beaches of Lake Huron, Canada. Water Air Soil Pollut. 2011, 220, 365-372. [CrossRef]

61. Li, Z.; Yi, X.; Zhou, H.; Chi, T.; Li, W.; Yang, K. Combined effect of polystyrene microplastics and dibutyl phthalate on the microalgae Chlorella pyrenoidosa. Environ. Pollut. 2020, 257, 113604. [CrossRef] 
62. De Leo, A.; Cutroneo, L.; Sous, D.; Stocchino, A. Settling Velocity of Microplastics Exposed to Wave Action. J. Mar. Sci. Eng. 2021, 9, 142. [CrossRef]

63. Stocchino, A.; De Leo, F.; Besio, G. Sea Waves Transport of Inertial Micro-Plastics: Mathematical Model and Applications. J. Mar. Sci. Eng. 2019, 7, 467. [CrossRef]

64. Bianco, A.; Passananti, M. Atmospheric micro and nanoplastics: An enormous microscopic problem. Sustainability 2020, 12,7327 [CrossRef]

65. Bianco, A.; Sordello, F.; Ehn, M.; Vione, D.; Passananti, M. Degradation of nanoplastics in the environment: Reactivity and impact on atmospheric and surface waters. Sci. Total Environ. 2020, 742, 140413. [CrossRef]

66. Willis, K.; Hardesty, B.D.; Vince, J.; Wilcox, C. The success of water refill stations reducing single-use plastic bottle litter. Sustainability 2019, 11, 5232. [CrossRef]

67. Scarr, S.; Hernandez, M. Drowning in Plastic. Available online: https://graphics.reuters.com/ENVIRONMENT-PLASTIC/0100 B275155/index.html (accessed on 7 April 2021).

68. Ocean Conservancy International Coastal Cleanup. Available online: https://oceanconservancy.org/wp-content/uploads/2020 /10/FINAL_2020ICC_Report.pdf (accessed on 6 April 2021).

69. Gjyli, L.; Vlachogianni, T.; Kolitari, J.; Matta, G.; Metalla, O.; Gjyli, S. Marine litter on the Albanian coastline: Baseline information for improved management. Ocean Coast. Manag. 2020, 187, 105108. [CrossRef]

70. Vlachogianni, T.; Skocir, M.; Constantin, P.; Labbe, C.; Orthodoxou, D.; Pesmatzoglou, I.; Scannella, D.; Spika, M.; Zissimopoulos, V.; Scoullos, M. Plastic pollution on the Mediterranean coastline: Generating fit-for-purpose data to support decision-making via a participatory-science initiative. Sci. Total Environ. 2020, 711, 135058. [CrossRef]

71. Simeonova, A.; Chuturkova, R. Marine litter accumulation along the Bulgarian Black Sea coast: Categories and predominance. Waste Manag. 2019, 84, 182-193. [CrossRef]

72. Brouwer, R.; Hadzhiyska, D.; Ioakeimidis, C.; Ouderdorp, H. The social costs of marine litter along European coasts. Ocean Coast. Manag. 2017, 138, 38-49. [CrossRef]

73. Botero, C.M.; Zielinski, S.; Pereira, C.I.; León, J.A.; Dueñas, L.F.; Puentes, V. The first report of deep-sea litter in the South-Western Caribbean Sea. Mar. Pollut. Bull. 2020, 157, 111327. [CrossRef]

74. Scotti, G.; Esposito, V.; D’Alessandro, M.; Panti, C.; Vivona, P.; Consoli, P.; Figurella, F.; Romeo, T. Seafloor litter along the Italian coastal zone: An integrated approach to identify sources of marine litter. Waste Manag. 2021, 124, 203-212. [CrossRef]

75. Gerigny, O.; Brun, M.; Fabri, M.-C.; Tomasino, C.; Le Moigne, M.; Jadaud, A.; Galgani, F. Seafloor litter from the continental shelf and canyons in French Mediterranean water: Distribution, typologies and trends. Mar. Pollut. Bull. 2019, 146, 653-666. [CrossRef]

76. Zhang, F.; Yao, C.; Xu, J.; Zhu, L.; Peng, G.; Li, D. Composition, spatial distribution and sources of plastic litter on the East China Sea floor. Sci. Total Environ. 2020, 742, 140525. [CrossRef]

77. Duncan, E.M.; Davies, A.; Brooks, A.; Chowdhury, G.W.; Godley, B.J.; Jambeck, J.; Maddalene, T.; Napper, I.; Nelms, S.E.; Rackstraw, C. Message in a bottle: Open source technology to track the movement of plastic pollution. PLoS ONE 2020, 15, e0242459. [CrossRef]

78. Geyer, R.; Jambeck, J.R.; Law, K.L. Production, use, and fate of all plastics ever made-Supplementary Information. Sci. Adv. 2017, 3, 19-24. [CrossRef]

79. Castelvetro, V.; Corti, A.; Bianchi, S.; Ceccarini, A.; Manariti, A.; Vinciguerra, V. Quantification of Poly(Ethylene terephthalate) micro-and nanoparticle contaminants in marine sediments and other environmental matrices. J. Hazard. Mater. 2020, 385, 121517. [CrossRef]

80. Zhang, F.; Wang, X.; Xu, J.; Zhu, L.; Peng, G.; Xu, P.; Li, D. Food-web transfer of microplastics between wild caught fish and crustaceans in East China Sea. Mar. Pollut. Bull. 2019, 146, 173-182. [CrossRef]

81. Gavigan, J.; Kefela, T.; Macadam-Somer, I.; Suh, S.; Geyer, R. Synthetic microfiber emissions to land rival those to waterbodies and are growing. PLoS ONE 2020, 15, e0237839. [CrossRef]

82. Rodríguez-Hernández, A.G.; Muñoz-Tabares, J.A.; Aguilar-Guzmán, J.C.; Vazquez-Duhalt, R. A novel and simple method for polyethylene terephthalate (PET) nanoparticle production. Environ. Sci. Nano 2019, 6, 2031-2036. [CrossRef]

83. Contaminants in the Marine Environment. Available online: https://ec.europa.eu/environment/marine/good-environmentalstatus.html (accessed on 19 March 2021).

84. Llorca, M.; Ábalos, M.; Vega-Herrera, A.; Adrados, M.A.; Abad, E.; Farré, M. Adsorption and Desorption Behaviour of Polychlorinated Biphenyls onto Microplastics' Surfaces in Water/Sediment Systems. Toxics 2020, 8, 59. [CrossRef]

85. Weber, R.; Herold, C.; Hollert, H.; Kamphues, J.; Ungemach, L.; Blepp, M.; Ballschmiter, K. Life cycle of PCBs and contamination of the environment and of food products from animal origin. Environ. Sci. Pollut. Res. 2018, 25, 16325-16343. [CrossRef] [PubMed]

86. Tang, H.P. Recent development in analysis of persistent organic pollutants under the Stockholm Convention. TrAC Trends Anal. Chem. 2013, 45, 48-66. [CrossRef]

87. Annex, C. Of the Stockholm Convention on Persistent Organic Pollutants; United Nations Environment Programme: Geneva, Switzerland, 2008; Volume 29.

88. Syberg, K.; Knudsen, C.M.H.; Tairova, Z.; Khan, F.R.; Shashoua, Y.; Geertz, T.; Pedersen, H.B.; Sick, C.; Mortensen, J.; Strand, J. Sorption of PCBs to environmental plastic pollution in the North Atlantic Ocean: Importance of size and polymer type. Case Stud. Chem. Environ. Eng. 2020, 2, 100062. [CrossRef] 
89. Anđelić, I.; Roje-Busatto, R.; Ujević, I.; Vuletić, N.; Matijević, S. Distribution of Bisphenol A in Sediment and Suspended Matter and Its Possible Impact on Marine Life in Kaštela Bay, Adriatic Sea, Croatia. J. Mar. Sci. Eng. 2020, 8, 480. [CrossRef]

90. Liu, X.; Shi, H.; Xie, B.; Dionysiou, D.D.; Zhao, Y. Microplastics as both a sink and a source of bisphenol A in the marine environment. Environ. Sci. Technol. 2019, 53, 10188-10196. [CrossRef]

91. Rochman, C.M.; Manzano, C.; Hentschel, B.T.; Simonich, S.L.M.; Hoh, E. Polystyrene plastic: A source and sink for polycyclic aromatic hydrocarbons in the marine environment. Environ. Sci. Technol. 2013, 47, 13976-13984. [CrossRef]

92. Salloum, M.J.; Chefetz, B.; Hatcher, P.G. Phenanthrene sorption by aliphatic-rich natural organic matter. Environ. Sci. Technol. 2002, 36, 1953-1958. [CrossRef]

93. Lima, A.L.C.; Farrington, J.W.; Reddy, C.M. Combustion-derived polycyclic aromatic hydrocarbons in the environment-A review. Environ. Forensics 2005, 6, 109-131. [CrossRef]

94. Kelly, B.C.; Ikonomou, M.G.; Blair, J.D.; Surridge, B.; Hoover, D.; Grace, R.; Gobas, F.A.P.C. Perfluoroalkyl contaminants in an Arctic marine food web: Trophic magnification and wildlife exposure. Environ. Sci. Technol. 2009, 43, 4037-4043. [CrossRef]

95. Ali, A.M.; Langberg, H.A.; Hale, S.E.; Kallenborn, R.; Hartz, W.F.; Mortensen, Å.-K.; Ciesielski, T.M.; McDonough, C.A.; Jenssen, B.M.; Breedveld, G.D. The fate of poly-and perfluoroalkyl substances in a marine food web influenced by land-based sources in the Norwegian Arctic. Environ. Sci. Process. Impacts 2021. [CrossRef]

96. Lionetto, M.G.; Caricato, R.; Giordano, M.E. Carbonic Anhydrase Sensitivity to Pesticides: Perspectives for Biomarker Development. Int. J. Mol. Sci. 2020, 21, 3562. [CrossRef]

97. Sharma, A.; Shukla, A.; Attri, K.; Kumar, M.; Kumar, P.; Suttee, A.; Singh, G.; Barnwal, R.P.; Singla, N. Global trends in pesticides: A looming threat and viable alternatives. Ecotoxicol. Environ. Saf. 2020, 201, 110812. [CrossRef]

98. Riascos-Flores, L.; Bruneel, S.; Van der Heyden, C.; Deknock, A.; Van Echelpoel, W.; Forio, M.A.E.; De Saeyer, N.; Berghe, W.V.; Spanoghe, P.; Bermudez, R. Polluted paradise: Occurrence of pesticide residues within the urban coastal zones of Santa Cruz and Isabela (Galapagos, Ecuador). Sci. Total Environ. 2021, 763, 142956. [CrossRef]

99. Han, J.; Shi, J.; Xie, Z.; Xu, J.; Guo, B. Synthesis, properties of biodegradable poly (butylene succinate-co-butylene 2methylsuccinate) and application for sustainable release. Materials 2019, 12, 1507. [CrossRef]

100. Pagano, M.; Stara, A.; Aliko, V.; Faggio, C. Impact of Neonicotinoids to Aquatic Invertebrates-In Vitro Studies on Mytilus galloprovincialis: A Review. J. Mar. Sci. Eng. 2020, 8, 801. [CrossRef]

101. Elessawy, N.A.; Gouda, M.H.; Ali, S.M.; Salerno, M.; Eldin, M.S. Effective Elimination of Contaminant Antibiotics Using High-Surface-Area Magnetic-Functionalized Graphene Nanocomposites Developed from Plastic Waste. Materials 2020, 13 , 1517. [CrossRef]

102. Mohammadi, L.; Rahdar, A.; Khaksefidi, R.; Ghamkhari, A.; Fytianos, G.; Kyzas, G.Z. Polystyrene Magnetic Nanocomposites as Antibiotic Adsorbents. Polymers 2020, 12, 1313. [CrossRef]

103. Godoy, V.; Martín-Lara, M.A.; Calero, M.; Blázquez, G. The relevance of interaction of chemicals/pollutants and microplastic samples as route for transporting contaminants. Process Saf. Environ. Prot. 2020, 138, 312-323. [CrossRef]

104. Guo, X.; Chen, C.; Wang, J. Sorption of sulfamethoxazole onto six types of microplastics. Chemosphere 2019, 228, 300-308. [CrossRef]

105. Opálková Šišková, A.; Dvorák, T.; Šimonová Baranyaiová, T.; Šimon, E.; Eckstein Andicsová, A.; Švajdlenková, H.; Opálek, A.; Krížik, P.; Nosko, M. Simple and Eco-Friendly Route from Agro-Food Waste to Water Pollutants Removal. Materials 2020, 13, 5424. [CrossRef]

106. Mistewicz, K.; Kępińska, M.; Nowak, M.; Sasiela, A.; Zubko, M.; Stróż, D. Fast and Efficient Piezo/Photocatalytic Removal of Methyl Orange Using SbSI Nanowires. Materials 2020, 13, 4803. [CrossRef] [PubMed]

107. Dąbek, L.; Picheta-Oleś, A.; Szelag, B.; Szulżyk-Cieplak, J.; Łagód, G. Modeling and Optimization of Pollutants Removal during Simultaneous Adsorption onto Activated Carbon with Advanced Oxidation in Aqueous Environment. Materials 2020, 13, 4220. [CrossRef] [PubMed]

108. Srivastava, N.K.; Majumder, C.B. Novel biofiltration methods for the treatment of heavy metals from industrial wastewater. J. Hazard. Mater. 2008, 151, 1-8. [CrossRef] [PubMed]

109. Brennecke, D.; Duarte, B.; Paiva, F.; Caçador, I.; Canning-Clode, J. Microplastics as vector for heavy metal contamination from the marine environment. Estuar. Coast. Shelf Sci. 2016, 178, 189-195. [CrossRef]

110. Godoy, V.; Blázquez, G.; Calero, M.; Quesada, L.; Martín-Lara, M.A. The potential of microplastics as carriers of metals. Environ. Pollut. 2019, 255, 113363. [CrossRef]

111. Piras, F.; Santoro, O.; Pastore, T.; Pio, I.; De Dominicis, E.; Gritti, E.; Caricato, R.; Lionetto, M.G.; Mele, G.; Santoro, D. Controlling micropollutants in tertiary municipal wastewater by $\mathrm{O}_{3} / \mathrm{H}_{2} \mathrm{O}_{2}$, granular biofiltration and $\mathrm{UV} 254 / \mathrm{H}_{2} \mathrm{O}_{2}$ for potable reuse applications. Chemosphere 2020, 239, 124635. [CrossRef]

112. Mele, C.; Lionetto, F.; Bozzini, B. An erosion-corrosion investigation of coated steel for applications in the oil and gas field, based on bipolar electrochemistry. Coatings 2020, 10, 92. [CrossRef]

113. Mele, C.; Boniardi, M.V.; Casaroli, A.; Degli Esposti, M.; Di Pietro, D.; Guastamacchia, P.; Bozzini, B. A comprehensive assessment of the performance of corrosion resistant alloys in hot acidic brines for application in oil and gas production. Corros. Eng. Sci. Technol. 2017, 52, 99-113. [CrossRef]

114. Bozzini, B.; D’Urzo, L.; Romanello, V.; Mele, C. Electrodeposition of Cu from acidic sulfate solutions in the presence of bis-(3sulfopropyl)-disulfide (SPS) and chloride ions. J. Electrochem. Soc. 2006, 153, C254. [CrossRef] 
115. Bozzini, B.; Gianoncelli, A.; Kourousias, G.; Boniardi, M.; Casaroli, A.; Dal Zilio, S.; Hussain, R.; Abyaneh, M.K.; Kiskinova, M.; Mele, $\mathrm{C}$. The role of chromium in the corrosion performance of cobalt-and cobalt-nickel based hardmetal binders: A study centred on X-ray absorption microspectroscopy. Int. J. Refract. Met. Hard Mater. 2020, 92, 105320. [CrossRef]

116. Abu-Nada, A.; McKay, G.; Abdala, A. Recent advances in applications of hybrid graphene materials for metals removal from wastewater. Nanomaterials 2020, 10, 595. [CrossRef]

117. Verla, A.W.; Enyoh, C.E.; Verla, E.N.; Nwarnorh, K.O. Microplastic-toxic chemical interaction: A review study on quantified levels, mechanism and implication. SN Appl. Sci. 2019, 1, 1-30. [CrossRef]

118. Prunier, J.; Maurice, L.; Perez, E.; Gigault, J.; Wickmann, A.-C.P.; Davranche, M.; Ter Halle, A. Trace metals in polyethylene debris from the North Atlantic subtropical gyre. Environ. Pollut. 2019, 245, 371-379. [CrossRef]

119. Wang, F.; Pan, Y.; Cai, P.; Guo, T.; Xiao, H. Single and binary adsorption of heavy metal ions from aqueous solutions using sugarcane cellulose-based adsorbent. Bioresour. Technol. 2017, 241, 482-490. [CrossRef]

120. Spilarewicz-Stanek, K.; Jakimińska, A.; Kisielewska, A.; Batory, D.; Piwoński, I. Understanding the Role of Silver Nanostructures and Graphene Oxide Applied as Surface Modification of $\mathrm{TiO}_{2}$ in Photocatalytic Transformations of Rhodamine B under UV and Vis Irradiation. Materials 2020, 13, 4653. [CrossRef]

121. Ashton, K.; Holmes, L.; Turner, A. Association of metals with plastic production pellets in the marine environment. Mar. Pollut. Bull. 2010, 60, 2050-2055. [CrossRef]

122. Dobaradaran, S.; Schmidt, T.C.; Nabipour, I.; Khajeahmadi, N.; Tajbakhsh, S.; Saeedi, R.; Mohammadi, M.J.; Keshtkar, M.; Khorsand, M.; Ghasemi, F.F. Characterization of plastic debris and association of metals with microplastics in coastline sediment along the Persian Gulf. Waste Manag. 2018, 78, 649-658. [CrossRef]

123. Zhou, Y.; Yang, Y.; Liu, G.; He, G.; Liu, W. Adsorption mechanism of cadmium on microplastics and their desorption behavior in sediment and gut environments: The roles of water $\mathrm{pH}$, lead ions, natural organic matter and phenanthrene. Water Res. 2020, 184, 116209. [CrossRef]

124. Kedzierski, M.; d’Almeida, M.; Magueresse, A.; Le Grand, A.; Duval, H.; César, G.; Sire, O.; Bruzaud, S.; Le Tilly, V. Threat of plastic ageing in marine environment. Adsorption/desorption of micropollutants. Mar. Pollut. Bull. 2018, 127, 684-694. [CrossRef]

125. Bozzini, B.; Mele, C.; D’Urzo, L. Electrodeposition of Cu from acidic sulphate solutions in the presence of PEG-Part II visible electroreflectance spectroscopy measurements during electrodeposition. J. Appl. Electrochem. 2006, 36, 87-96. [CrossRef]

126. Bozzini, B.; D’Urzo, L.; Mele, C. Electrodeposition of Cu from cyanoalkaline solutions in the presence of CPC and PEG: An electrochemical and in situ SERS investigation. J. Electrochem. Soc. 2005, 152, C255. [CrossRef]

127. Abbasi, S.; Moore, F.; Keshavarzi, B.; Hopke, P.K.; Naidu, R.; Rahman, M.M.; Oleszczuk, P.; Karimi, J. PET-microplastics as a vector for heavy metals in a simulated plant rhizosphere zone. Sci. Total Environ. 2020, 744, 140984. [CrossRef] [PubMed]

128. Campanale, C.; Massarelli, C.; Savino, I.; Locaputo, V.; Uricchio, V.F. A detailed review study on potential effects of microplastics and additives of concern on human health. Int. J. Environ. Res. Public Health 2020, 17, 1212. [CrossRef] [PubMed]

129. Hirt, N.; Body-Malapel, M. Immunotoxicity and intestinal effects of nano-and microplastics: A review of the literature. Part. Fibre Toxicol. 2020, 17, 1-22. [CrossRef] [PubMed]

130. Hazardous Substances in Marine Organisms. Available online: https://www.eea.europa.eu/data-and-maps/indicators/ hazardous-substances-in-marine-organisms/hazardous-substances-in-marine-organisms-1 (accessed on 8 April 2021).

131. Wang, F.; Zhang, M.; Sha, W.; Wang, Y.; Hao, H.; Dou, Y.; Li, Y. Sorption behavior and mechanisms of organic contaminants to nano and microplastics. Molecules 2020, 25, 1827. [CrossRef] [PubMed]

132. Atugoda, T.; Vithanage, M.; Wijesekara, H.; Bolan, N.; Sarmah, A.K.; Bank, M.S.; You, S.; Ok, Y.S. Interactions between microplastics, pharmaceuticals and personal care products: Implications for vector transport. Environ. Int. 2021, 149 , 106367. [CrossRef]

133. Zhu, L.; Chen, B. Sorption behavior of p-nitrophenol on the interface between anion- cation organobentonite and water. Environ. Sci. Technol. 2000, 34, 2997-3002. [CrossRef]

134. Tourinho, P.S.; Kočí, V.; Loureiro, S.; van Gestel, C.A.M. Partitioning of chemical contaminants to microplastics: Sorption mechanisms, environmental distribution and effects on toxicity and bioaccumulation. Environ. Pollut. 2019, 252, $1246-1256$. [CrossRef]

135. Bakir, A.; Rowland, S.J.; Thompson, R.C. Enhanced desorption of persistent organic pollutants from microplastics under simulated physiological conditions. Environ. Pollut. 2014, 185, 16-23. [CrossRef]

136. Mei, W.; Chen, G.; Bao, J.; Song, M.; Li, Y.; Luo, C. Interactions between microplastics and organic compounds in aquatic environments: A mini review. Sci. Total Environ. 2020, 736, 139472. [CrossRef]

137. Guo, X.; Pang, J.; Chen, S.; Jia, H. Sorption properties of tylosin on four different microplastics. Chemosphere 2018, 209, 240-245. [CrossRef]

138. Zhang, H.; Wang, J.; Zhou, B.; Zhou, Y.; Dai, Z.; Zhou, Q.; Chriestie, P.; Luo, Y. Enhanced adsorption of oxytetracycline to weathered microplastic polystyrene: Kinetics, isotherms and influencing factors. Environ. Pollut. 2018, 243, 1550-1557. [CrossRef]

139. Guo, X.; Wang, X.; Zhou, X.; Kong, X.; Tao, S.; Xing, B. Sorption of four hydrophobic organic compounds by three chemically distinct polymers: Role of chemical and physical composition. Environ. Sci. Technol. 2012, 46, 7252-7259. [CrossRef]

140. Velzeboer, I.; Kwadijk, C.; Koelmans, A.A. Strong sorption of PCBs to nanoplastics, microplastics, carbon nanotubes, and fullerenes. Environ. Sci. Technol. 2014, 48, 4869-4876. [CrossRef] 
141. Wu, C.; Zhang, K.; Huang, X.; Liu, J. Sorption of pharmaceuticals and personal care products to polyethylene debris. Environ. Sci. Pollut. Res. 2016, 23, 8819-8826. [CrossRef]

142. Li, Y.; Li, M.; Li, Z.; Yang, L.; Liu, X. Effects of particle size and solution chemistry on Triclosan sorption on polystyrene microplastic. Chemosphere 2019, 231, 308-314. [CrossRef]

143. Lee, H.; Shim, W.J.; Kwon, J.-H. Sorption capacity of plastic debris for hydrophobic organic chemicals. Sci. Total Environ. 2014, 470, 1545-1552. [CrossRef]

144. Mato, Y.; Isobe, T.; Takada, H.; Kanehiro, H.; Ohtake, C.; Kaminuma, T. Plastic resin pellets as a transport medium for toxic chemicals in the marine environment. Environ. Sci. Technol. 2001, 35, 318-324. [CrossRef]

145. Karapanagioti, H.K.; Klontza, I. Testing phenanthrene distribution properties of virgin plastic pellets and plastic eroded pellets found on Lesvos island beaches (Greece). Mar. Environ. Res. 2008, 65, 283-290. [CrossRef]

146. Wu, B.; Taylor, C.M.; Knappe, D.R.U.; Nanny, M.A.; Barlaz, M.A. Factors controlling alkylbenzene sorption to municipal solid waste. Environ. Sci. Technol. 2001, 35, 4569-4576. [CrossRef]

147. Rochman, C.M.; Hoh, E.; Hentschel, B.T.; Kaye, S. Long-term field measurement of sorption of organic contaminants to five types of plastic pellets: Implications for plastic marine debris. Environ. Sci. Technol. 2013, 47, 1646-1654. [CrossRef] [PubMed]

148. Mao, J.-D.; Hundal, L.S.; Thompson, M.L.; Schmidt-Rohr, K. Correlation of poly (methylene)-rich amorphous aliphatic domains in humic substances with sorption of a nonpolar organic contaminant, phenanthrene. Environ. Sci. Technol. 2002, 36, 929-936. [CrossRef] [PubMed]

149. Endo, S.; Takizawa, R.; Okuda, K.; Takada, H.; Chiba, K.; Kanehiro, H.; Ogi, H.; Yamashita, R.; Date, T. Concentration of polychlorinated biphenyls (PCBs) in beached resin pellets: Variability among individual particles and regional differences. Mar. Pollut. Bull. 2005, 50, 1103-1114. [CrossRef] [PubMed]

150. Mrozik, W.; Stefańska, J. Adsorption and biodegradation of antidiabetic pharmaceuticals in soils. Chemosphere 2014, 95, 281-288. [CrossRef]

151. Torres, F.G.; Dioses-Salinas, D.C.; Pizarro-Ortega, C.I.; De-la-Torre, G.E. Sorption of chemical contaminants on degradable and non-degradable microplastics: Recent progress and research trends. Sci. Total Environ. 2020, 757, 143875. [CrossRef]

152. Wang, J.; Guo, X. Adsorption kinetic models: Physical meanings, applications, and solving methods. J. Hazard. Mater. 2020, 390, 122156. [CrossRef]

153. El-Khaiary, M.I.; Malash, G.F.; Ho, Y.-S. On the use of linearized pseudo-second-order kinetic equations for modeling adsorption systems. Desalination 2010, 257, 93-101. [CrossRef]

154. Ho, Y.-S. Isotherms for the sorption of lead onto peat: Comparison of linear and non-linear methods. Polish J. Environ. Stud. 2006, $15,81-86$.

155. Ho, Y.-S. Review of second-order models for adsorption systems. J. Hazard. Mater. 2006, 136, 681-689. [CrossRef]

156. Kumar, K.V.; Sivanesan, S. Pseudo second order kinetics and pseudo isotherms for malachite green onto activated carbon: Comparison of linear and non-linear regression methods. J. Hazard. Mater. 2006, 136, 721-726. [CrossRef]

157. Guo, X.; Wang, J. A general kinetic model for adsorption: Theoretical analysis and modeling. J. Mol. Liq. 2019, 288, 111100. [CrossRef]

158. Turner, A.; Holmes, L.A. Adsorption of trace metals by microplastic pellets in fresh water. Environ. Chem. 2015, 12, 600-610. [CrossRef]

159. Lagergren, S.K. About the theory of so-called adsorption of soluble substances. Sven. Vetenskapsakad. Handingarl 1898, $24,1-39$.

160. Ho, Y.S.; Wase, D.A.J.; Forster, C.F. Removal of lead ions from aqueous solution using sphagnum moss peat as adsorbent. Water $S A$ 1996, 22, 219-224.

161. Hu, J.-Q.; Yang, S.-Z.; Guo, L.; Xu, X.; Yao, T.; Xie, F. Microscopic investigation on the adsorption of lubrication oil on microplastics. J. Mol. Liq. 2017, 227, 351-355. [CrossRef]

162. Xu, P.; Ge, W.; Chai, C.; Zhang, Y.; Jiang, T.; Xia, B. Sorption of polybrominated diphenyl ethers by microplastics. Mar. Pollut. Bull. 2019, 145, 260-269. [CrossRef]

163. Zhang, J. Physical insights into kinetic models of adsorption. Sep. Purif. Technol. 2019, 229, 115832. [CrossRef]

164. Boyd, G.E.; Adamson, A.W.; Myers, L.S. The Exchange Adsorption of Ions from Aqueous Solutions by Organic Zeolites. II. Kinetics. J. Am. Chem. Soc. 1947, 69, 2836-2848. [CrossRef] [PubMed]

165. Ofomaja, A.E. Intraparticle diffusion process for lead (II) biosorption onto mansonia wood sawdust. Bioresour. Technol. 2010, 101, 5868-5876. [CrossRef]

166. Ala'a, H.; Ibrahim, K.A.; Albadarin, A.B.; Ali-Khashman, O.; Walker, G.M.; Ahmad, M.N.M. Remediation of phenol-contaminated water by adsorption using poly (methyl methacrylate)(PMMA). Chem. Eng. J. 2011, 168, 691-699.

167. Langmuir, I. The adsorption of gases on plane surfaces of glass, mica and platinum. J. Am. Chem. Soc. 1918, 40, 1361-1403. [CrossRef]

168. Hu, Y.; Guo, X.; Chen, C.; Wang, J. Algal sorbent derived from Sargassum horneri for adsorption of cesium and strontium ions: Equilibrium, kinetics, and mass transfer. Appl. Microbiol. Biotechnol. 2019, 103, 2833-2843. [CrossRef] [PubMed]

169. Vadi, M.; Mansoorabad, A.O.; Mohammadi, M.; Rostami, N. Investigation of Langmuir, Freundlich and Temkin adsorption isotherm of tramadol by multi-wall carbon nanotube. Asian J. Chem. 2013, 25, 5467. [CrossRef]

170. Nguyen, C.; Do, D.D. The Dubinin-Radushkevich equation and the underlying microscopic adsorption description. Carbon 2001, 39, 1327-1336. [CrossRef] 
171. Al-Jabari, M. Kinetic models for adsorption on mineral particles comparison between Langmuir kinetics and mass transfer. Environ. Technol. Innov. 2016, 6, 27-37. [CrossRef]

172. Marczewski, A.W.; Deryło-Marczewska, A.; Słota, A. Adsorption and desorption kinetics of benzene derivatives on mesoporous carbons. Adsorption 2013, 19, 391-406. [CrossRef]

173. Marczewski, A.W. Extension of Langmuir kinetics in dilute solutions to include lateral interactions according to regular solution theory and the Kiselev association model. J. Colloid Interface Sci. 2011, 361, 603-611. [CrossRef]

174. Hatch, C.D.; Wiese, J.S.; Crane, C.C.; Harris, K.J.; Kloss, H.G.; Baltrusaitis, J. Water adsorption on clay minerals as a function of relative humidity: Application of BET and Freundlich adsorption models. Langmuir 2012, 28, 1790-1803. [CrossRef]

175. Liu, Z.; Qin, Q.; Hu, Z.; Yan, L.; Ieong, U.-I.; Xu, Y. Adsorption of chlorophenols on polyethylene terephthalate microplastics from aqueous environments: Kinetics, mechanisms and influencing factors. Environ. Pollut. 2020, 265, 114926. [CrossRef]

176. Hüffer, T.; Hofmann, T. Sorption of non-polar organic compounds by micro-sized plastic particles in aqueous solution. Environ. Pollut. 2016, 214, 194-201. [CrossRef]

177. Liu, P.; Zhan, X.; Wu, X.; Li, J.; Wang, H.; Gao, S. Effect of weathering on environmental behavior of microplastics: Properties, sorption and potential risks. Chemosphere 2020, 242, 125193. [CrossRef] [PubMed]

178. Hüffer, T.; Weniger, A.-K.; Hofmann, T. Sorption of organic compounds by aged polystyrene microplastic particles. Environ. Pollut. 2018, 236, 218-225. [CrossRef] [PubMed]

179. Abad, P.; Arroyo-Manzanares, N.; Rivas-Montoya, E.; Ochando-Pulido, J.M.; Guillamon, E.; García-Campaña, A.M.; MartinezFerez, A. Effects of different vehiculization strategies for the allium derivative propyl propane thiosulfonate during dynamic simulation of the pig gastrointestinal tract. Can. J. Anim. Sci. 2018, 99, 244-253. [CrossRef]

180. Song, X.; Wu, X.; Song, X.; Shi, C.; Zhang, Z. Sorption and desorption of petroleum hydrocarbons on biodegradable and nondegradable microplastics. Chemosphere 2020, 128553. [CrossRef]

181. Zhou, X.; Wei, J.; Liu, K.; Liu, N.; Zhou, B. Adsorption of bisphenol A based on synergy between hydrogen bonding and hydrophobic interaction. Langmuir 2014, 30, 13861-13868. [CrossRef]

182. Zuo, L.-Z.; Li, H.-X.; Lin, L.; Sun, Y.-X.; Diao, Z.-H.; Liu, S.; Zhang, Z.-Y.; Xu, X.-R. Sorption and desorption of phenanthrene on biodegradable poly (butylene adipate co-terephthalate) microplastics. Chemosphere 2019, 215, 25-32. [CrossRef]

183. Wang, F.; Shih, K.M.; Li, X.Y. The partition behavior of perfluorooctanesulfonate (PFOS) and perfluorooctanesulfonamide (FOSA) on microplastics. Chemosphere 2015, 119, 841-847. [CrossRef]

184. Li, J.; Zhang, K.; Zhang, H. Adsorption of antibiotics on microplastics. Environ. Pollut. 2018, 237, 460-467. [CrossRef]

185. Llorca, M.; Schirinzi, G.; Martínez, M.; Barceló, D.; Farré, M. Adsorption of perfluoroalkyl substances on microplastics under environmental conditions. Environ. Pollut. 2018, 235, 680-691. [CrossRef]

186. Cortés-Arriagada, D. Elucidating the co-transport of bisphenol A with polyethylene terephthalate (PET) nanoplastics: A theoretical study of the adsorption mechanism. Environ. Pollut. 2021, 270, 116192. [CrossRef]

187. Wang, Q.; Zhang, Y.; Wangjin, X.; Wang, Y.; Meng, G.; Chen, Y. The adsorption behavior of metals in aqueous solution by microplastics effected by UV radiation. J. Environ. Sci. 2020, 87, 272-280. [CrossRef] [PubMed]

188. Rochman, C.M.; Hentschel, B.T.; Teh, S.J. Long-term sorption of metals is similar among plastic types: Implications for plastic debris in aquatic environments. PLoS ONE 2014, 9, e85433. [CrossRef] [PubMed]

189. Richard, H.; Carpenter, E.J.; Komada, T.; Palmer, P.T.; Rochman, C.M. Biofilm facilitates metal accumulation onto microplastics in estuarine waters. Sci. Total Environ. 2019, 683, 600-608. [CrossRef] [PubMed]

190. Kedzierski, M.; Villain, J.; Falcou-Préfol, M.; Kerros, M.E.; Henry, M.; Pedrotti, M.L.; Bruzaud, S. Microplastics in Mediterranean Sea: A protocol to robustly assess contamination characteristics. PLoS ONE 2019, 14, e0212088. [CrossRef]

191. Bakir, A.; Rowland, S.J.; Thompson, R.C. Competitive sorption of persistent organic pollutants onto microplastics in the marine environment. Mar. Pollut. Bull. 2012, 64, 2782-2789. [CrossRef]

192. Zhang, S.; Han, B.; Sun, Y.; Wang, F. Microplastics influence the adsorption and desorption characteristics of Cd in an agricultural soil. J. Hazard. Mater. 2020, 388, 121775. [CrossRef]

193. Holmes, L.A.; Turner, A.; Thompson, R.C. Adsorption of trace metals to plastic resin pellets in the marine environment. Environ. Pollut. 2012, 160, 42-48. [CrossRef]

194. Zhang, H.; Pap, S.; Taggart, M.A.; Boyd, K.G.; James, N.A.; Gibb, S.W. A review of the potential utilisation of plastic waste as adsorbent for removal of hazardous priority contaminants from aqueous environments. Environ. Pollut. 2020, $258,113698$. [CrossRef]

195. Johansen, M.P.; Prentice, E.; Cresswell, T.; Howell, N. Initial data on adsorption of Cs and Sr to the surfaces of microplastics with biofilm. J. Environ. Radioact. 2018, 190, 130-133. [CrossRef]

196. Ateia, M.; Zheng, T.; Calace, S.; Tharayil, N.; Pilla, S.; Karanfil, T. Sorption behavior of real microplastics (MPs): Insights for organic micropollutants adsorption on a large set of well-characterized MPs. Sci. Total Environ. 2020, 720, 137634. [CrossRef]

197. Wang, Z.; Chen, M.; Zhang, L.; Wang, K.; Yu, X.; Zheng, Z.; Zheng, R. Sorption behaviors of phenanthrene on the microplastics identified in a mariculture farm in Xiangshan Bay, southeastern China. Sci. Total Environ. 2018, 628, 1617-1626. [CrossRef]

198. Leslie, H.A.; Depledge, M.H. Where is the evidence that human exposure to microplastics is safe? Environ. Int. 2020, $142,105807$. [CrossRef] 